\title{
Travelling waves for finding the fault location in transmission lines
}

\author{
Mohammad Abdul Baseer \\ Electrical and Electronics Engineering, Al Majmaah University, Riyadh, K.S.A. \\ Email address: \\ m.abdulbaseer@mu.edu.sa (M. A. Baseer),mabaseer703@gmail.com (M. A. Baseer)
}

\section{To cite this article:}

Mohammad Abdul Baseer. Travelling Waves for Finding the Fault Location in Transmission Lines, Journal Electrical and Electronic Engineering. Vol. 1, No. 1, 2013, pp. 1-19. doi: 10.11648/j.jeee.20130101.11

\begin{abstract}
Transmission lines are designed to transfer electric power from source locations to distribution networks. This project investigates the problem of fault localization using traveling wave voltage and current signals obtained at a single end of a transmission line and multi ends of a transmission network. Fourier transform (FT) is the most popular transformation that can be applied to traveling wave signals to obtain their frequency components appearing in the fault signal. The wavelet multi resolution analysis is a new and powerful method of signal analysis and is well suited to traveling wave signals. Wavelets can provide multiple resolutions in both time and frequency domains.
\end{abstract}

Keywords: Transmission Lines, Wavelet Theory, Fourier Transforms, Fault Analysis, Localisation Of Faults

\section{Introduction}

An electric power system comprises of generation, transmission and distribution of electric energy. Transmission lines are used to transmit electric power to distant large load centres. The rapid growth of electric power systems over the past few decades has resulted in a large increase of the number of lines in operation and their total length. These lines are exposed to faults as a result of lightning, short circuits, faulty equipments, mis operation, human errors, overload, and aging. Many electrical faults manifest in mechanical damages, which must be repaired before returning the line to service. The restoration can be expedited if the fault location is either known or can be estimated with a reasonable accuracy. Faults cause short to long term power outages for customers and may lead to significant losses especially for the manufacturing industry. Fast detecting, isolating, locating and repairing of these faults are critical in maintaining a reliable power system operation. When a fault occurs on a transmission line, the voltage at the point of fault suddenly reduces to a low value. This sudden change produces a high frequency electromagnetic impulse called the travelling wave (TW). These travelling waves propagate away from the fault in both directions at speeds close to that of light. To find the fault, the captured signal from instrument transformers has to be filtered and analyzed using different signal processing tools. Then, the filtered signal is used to detect and locate the fault. It is necessary to measure the value, polarity, phase, and time delay of the incoming wave to find the fault location accurately. The main objective of this thesis is to analyze the methods of the fault location based on the theory of travelling waves in high voltage transmission lines.

In this thesis, we have developed single and multi end methods of travelling wave fault location which use current signal recordings of the $500 \mathrm{kV}$ network obtained from travelling wave recorders (TWR) sparsely located in the transmission network. The TWRs are set to record 4 milliseconds of data using an 8 bit resolution and a sampling rate of $1.25 \mathrm{MHz}$. The record includes both pre trigger and post trigger data. Although the single ended fault location method is less expensive than the double ended method, since only one unit is required per line and communication link is not required, the errors remain high when using the advanced signal processing techniques. Furthermore, the fault location error needs more improvement considering single end method. Multi end method shows a promising economical solution considering few recording units.

\section{Literature Survey}

A detailed literature survey has to classify the fault and to estimate the fault location. The areas of the work and results obtained by the various researchers are summarized in the chapter.

Lin Yong Wu et.al [1] explored A New Single Ended 
Fault Location Technique Using Travelling Wave Natural Frequencies. In this paper the relationship between the spectra of travelling waves, the fault distance and the terminal conditions of transmission lines is discussed.

Sima wenxia et.al [2] proposed a Fault location for transmission line based on travelling waves using correlation analysis method. In this paper the principle of transmission line fault location based on travelling waves. The principle and of correlation analysis is introduced, then the method using correlation analysis in fault location is given.

Bian Haihong et.al [3] discussed a Study of Fault Location for Parallel Transmissions Lines Using One Terminal Current Travelling Waves the application of fault location using one terminal travelling wave for parallel transmission lines. With proper phase module transformation, parallel lines can be decomposed to the same directional net and the reverse directional net. This paper analyzes the propagation characteristics of travelling waves in the reverse directional net, and derivates the refraction coefficient at the fault point for a single phase fault firstly and strictly.

ZOU Gui bin et.al [4] developed an Algorithm for Ultra High Speed Travelling Wave Protection with Accurate Fault Location. In this paper Basing fault generated current travelling wave, a novel algorithm implementing ultra high speed protection and fault location for transmission lines is proposed.

\section{Power System Faults}

\subsection{Introduction}

Power transmission and distribution lines are the vital links that achieve the essential continuity of service of electrical power to the end users. Transmission lines connect the generating stations and load centres.

\subsection{Nature and Causes of Faults}

Faults are caused either by insulation failures and conducting path failures. Most of the faults on transmission and distribution lines are caused by over voltage due to lighting and switching surges or by external conducting objects falling on over head lines. Birds, tree branches may also cause faults on over head lines. Other causes of faults on over head lines are direct lightning strokes, aircraft, snakes, ice and snow loading, storms, earthquakes, creepers etc. In the case of cables, transformers, generators the causes may be failure of solid insulation due to ageing, heat, moisture or over voltage, accidental contact with earth etc.

The over all faults can be classified as two types

1. Series faults

2. Shunt faults

\begin{tabular}{|l|c|c|l|}
\hline Type of Fault & Symbol & \% Occurvence & Severity \\
\hline Line to Ground & L-G & $75-80$ & very less severe \\
\hline Line to Line & L-L & $10-15$ & less severe \\
\hline $\begin{array}{l}\text { Double Line to } \\
\text { Ground }\end{array}$ & 2L-G & $5-10$ & severe \\
\hline Three phase & $3-\phi$ & $2-5$ & very severe \\
\hline
\end{tabular}

\subsection{Effects of Faults}

A fault if unlearned has the following effects on a power system.

- Heavy short circuit current may cause damage to equipment or any other element of the power system due to over heating or flash over and high mechanical forces set up due to heavy current.

- There may be reduction in the supply voltage of the healthy feeders, resulting in the loss of industrial loads. Short circuits may cause the unbalancing of the supply voltages and currents, there by heating rotating machines.

- $\quad$ There may be a loss of system stability. The faults may cause an interruption of supply to consumers.

\section{Basic Concepts of Fault Location Process}

\subsection{Historical Background}

A few years ago, most power companies elected to have little or no investment for improving fault location methods. This is mainly due to a belief that most of the faults are transient ones needing no information about their locations. Also, the weak or in accurate behaviour of the earlier fault locators may have played a role in this belief. On the other hand, a huge amount of research contributions were presented for fault location purposes as reported in the literatures. However, these efforts received little consideration from these companies. These viewpoints are recently changed due to the new concepts of free marketing and de regulation all over the world. These competitive markets force the companies to change their policies to save money and time as well as to provide a better service. This consequently leads to increasingly consider the benefits of fault location estimation methods. Nowadays, it is quite common for almost all modern versions of multi function line protection units to include separate routines for fault Location calculation.

\subsection{Properties of Transmission Line Faults}

Transmission lines are considered the most vital components in power systems connecting both generating and consumer areas with huge interconnected networks. They consist of a group of overhead conductors spreading in a wide area in different geographical and weather circumstances. These conductors are dispensed on a special metallic structure "towers", in which the conductors are separated from the tower body with some insulating compo- 
nents and from each other with an adequate spacing to allow the air to serve as a sufficient insulation among them. Unfortunately these conductors are frequently subjected to a wide variety of fault types. Thus, providing proper protection functions for them is an attractive area for research specialists. Different types of faults can occur including phase faults among two or more different conductors or ground faults including one or more conductors to ground types. However, the dominant type of these faults is ground ones.

\subsection{Fault Location Estimation Benefits}

\subsubsection{Time and Effort Saving}

After the fault, the related relaying equipment enables the associated circuit breakers to De energize the faulted sections. Once the fault is cleared and the participated faulted phase(s) are declared, the adopted fault locator is enabled to detect the fault position. Then, the maintenance crews can be informed of that location in order to fix the resultant damage. Later, the line can be reenergized again after finishing the maintenance task. Since transmission line networks spread for some hundreds of kilometres in different environmental and geographical circumstances, locating these faults based on the human experience and the available information about the status of all breakers in the faulted area is not efficient and time consuming. These efforts can therefore effectively help to sectionalize the fault (declare the faulted line section) rather than to locate precisely the fault position. Thus the importance of employing dedicated fault location Schemes are obvious.

\subsubsection{Improving the System Availability}

There is no doubt that fast and effective maintenance processes directly lead to improve the power availability to the consumers. This consequently enhances the overall efficiency of the power nets. These concepts of (availability, efficiency, quality .... etc) have an increasingly importance nowadays due to the new marketing policies resulting from deregulation and liberalization of power and energy markets.

\subsubsection{Assisting Future Maintenance Plans}

It is quite right that temporary faults (the most dominant fault on overhead lines) are self cleared and hence the system continuity is not permanently affected. However, analyzing the location of these faults can help to pinpoint the wake spots on the overall transmission nets effectively. This hopefully assists the future plans of maintenance schedules and consequently leads to avoid further problems in the future. These strategies of preventive maintenance enable to avoid those large problems such as blackouts and help to increase the efficiency of the overall power system.

\subsubsection{Economic Factor}

All the mentioned benefits can be reviewed from the economical perspective. There is no doubt that time and effort saving, increasing the power availability and avoiding future accidents can be directly interpreted as a cost reduction or a profit increasing. This is an essential concept for competitive marketing.

\subsection{Classification of Developed Fault Location Methods}

Generally speaking, fault location methods can be classified into two basic groups, travelling wave based schemes and impedance measurement based ones as shown in Fig. 1. Travelling wave schemes can be used either with injecting a certain travelling wave from the locator position or with analyzing the generated transients due to the fault occurrence. Impedance measurement schemes are classified whether they depend on the data from one or both line ends.

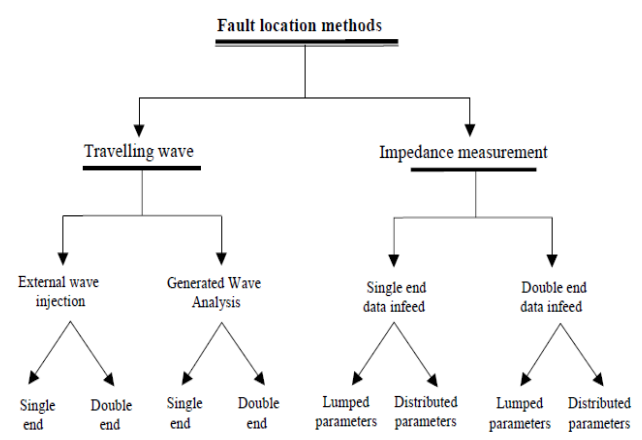

Fig. 1. Classification of fault location methods.

\subsubsection{Travelling Wave Based Fault Locators}

Employing travelling wave phenomena for fault location purposes for both underground cables and overhead lines was reported since 1931. In 1951, Lewis classified travelling wave based schemes into different four types A, B, C and $\mathrm{D}$ according to their modes of operation using the travelling voltage waves. Types $\mathrm{A}$ and $\mathrm{D}$ depend on analyzing the resulting transients from the fault itself needing no further pulse generating circuitry. Type $\mathrm{A}$ is a single end one capturing the transients only at one end. It relies on the generated transients from the arcing flashover during the fault. However the assumption of getting generated transients at the line end is not always satisfied. Moreover, the arc itself may extinguish rapidly. They rely on measuring the required time for the injected pulses to go and to be captured after reflection from the fault point. This time can be directly interpreted as a fault distance.

\subsubsection{Impedance Measurement Based Fault Locators}

These schemes provide another alternative for the fault location estimation problem. Fig. 2. shows the one line diagram of a three phase double infeed faulted transmission line. A line to ground fault occurred on phase $\mathrm{A}$ at point $\mathrm{F}$ through a resistance RF at a distance $x$ from the locator position. The fault current IF is comprised from two components IFs and IFr flowing from sending and receiving ends respectively. The essential task of the fault location algorithm is to estimate the fault distance $x$ as a function of the total line impedance ZL using the sending end measurements (for single end algorithms) or both end measurements (for double end algorithms)with the most possible accuracy. 


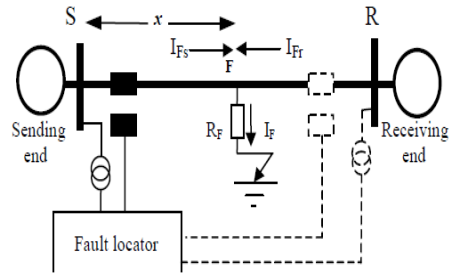

Fig. 2. One line diagram of a faulted transmission line.

\subsubsection{Non Conventional Fault Locators}

Instead of the normal mathematical derivation, non conventional fault location algorithms were introduced depending on other processing platforms such as Wavelet Transform (WT), ANN or GA. These methods have their own problems that result from the line modelling accuracy, data availability and the method essences.

\subsection{Requirements for Fault Location Process}

Fig. 3 presents a general explanation of the essential requirements for fault locators. Generally speaking, fault locator works in off line mode after performing the relaying action. Once the fault is detected and the faulty phase(s) are successfully classified, the fault locator is enabled to find out the estimated fault distance. The recorded data by the Digital Fault Recorder (DFR) is passed through the locator input manipulator to the fault locator.

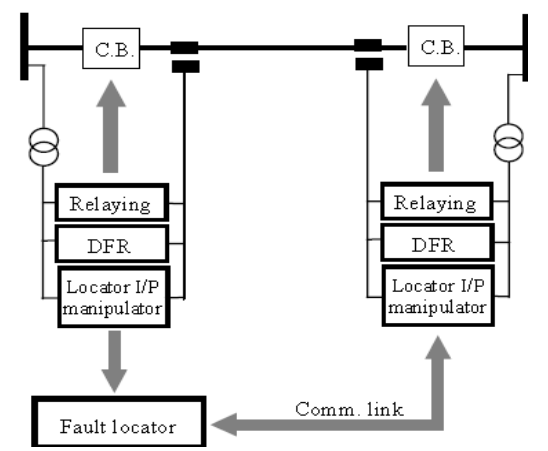

Fig. 3. General requirements for fault location schemes.

\section{Travelling Wave Theory}

Studies of transient disturbances on transmission systems have shown that changes are followed by travelling waves, which at first approximation can be treated as step front waves. As this research is focused on travelling wave based fault location, it was decided to employ an introductory chapter to the basic theory of travelling waves.

\subsection{Introduction}

The transmission line conductors have resistances and inductances distributed uniformly along the length of the line. Travelling wave fault location methods are usually more suitable for application to long lines.

\subsection{The Transmission Line Equation}

A transmission line is a system of conductors connecting one point to another and along which electromagnetic energy can be sent. Power transmission lines are a typical example of transmission lines. The transmission line equations that govern general two conductor uniform transmission lines, including two and three wire lines, and coaxial cables, are called the telegraph equations. The general transmission line equations are named the telegraph equations because they were formulated for the first time by Oliver Heaviside (1850 1925) when he was employed by a telegraph company and used to investigate disturbances on telephone wires. When one considers a line segment $\mathrm{dx}$ with parameters resistance ( $R$ ), conductance ( $G$ ), inductance ( L ), and capacitance ( C ), all per unit length, (see Figure 2.1 the line constants for segment $d x$ are $R d x, G d x$, $\mathrm{L} \mathrm{dx}$, and $\mathrm{C} \mathrm{dx}$. The electric flux $\psi$ and the magnetic flux $\varphi$ created by the electromagnetic wave, which causes the instantaneous voltage $\mathrm{u}(\mathrm{x}, \mathrm{t})$ and current $\mathrm{i}(\mathrm{x}, \mathrm{t})$, are

$$
d \psi(t)=u(x, t) C \mathrm{~d} x
$$

And

$$
d \varphi(t)=i(x, t) L \mathrm{~d} x
$$

Calculating the voltage drop in the positive direction of $x$ of the distance $d x$ obtains

$$
\begin{aligned}
& u(x, t)-u(x+d x, t)= \\
& -d u(x, t)=-\frac{\partial u(x, t)}{\partial x} d x= \\
& \left(R+L \frac{\partial}{\partial t}\right) i(x, t) d x
\end{aligned}
$$

If $d x$ is cancelled from both sides of (3), the voltage equation becomes

$$
\begin{aligned}
& \frac{\partial u(x, t)}{\partial x}= \\
& -L \frac{\partial i(x, t)}{\partial t}-R i(x, t)
\end{aligned}
$$

Similarly, for the current owing through $G$ and the current charging $\mathrm{C}$, Kirchhoff's current law can be applied as

$$
\begin{aligned}
& i(x, t)-i(x+d x, t)= \\
& -d i(x, t)=-\frac{\partial i(x, t)}{\partial x}= \\
& \left(G+C \frac{\partial}{\partial t}\right) u(x, t) d x
\end{aligned}
$$

If $d x$ is cancelled from both sides of (5), the current equation becomes

$$
\begin{aligned}
& \frac{\partial i(x, t)}{\partial x}= \\
& -C \frac{\partial u(x, t)}{\partial t}-G u(x, t)
\end{aligned}
$$


The negative sign in these equations is caused by the fact that when the current and voltage waves propagate in the positive $\mathrm{x}$ direction, $\mathrm{i}(\mathrm{x}, \mathrm{t})$ and $\mathrm{u}(\mathrm{x}, \mathrm{t})$ will decrease in amplitude for increasing $x$. When one substitutes and differentiate once more with respect to $\mathrm{x}$, we get the second order partial differential equations $Z=R+\frac{\partial L(x, t)}{\partial t}$ and $\boldsymbol{Y}=\boldsymbol{G}+\frac{\partial \boldsymbol{C}(\boldsymbol{x}, \boldsymbol{t})}{\partial t}$ and differentiate once more with respect to $\mathrm{x}$, we get the second order partial differential equations

$$
\begin{aligned}
& \frac{\partial^{2} i(x, t)}{\partial x^{2}}=-Y \frac{\partial u(x, t)}{\partial t}= \\
& Y Z i(x, t)=\gamma^{2} i(x, t) \\
& \frac{\partial^{2} i(x, t)}{\partial x^{2}}=-Y \frac{\partial u(x, t)}{\partial t}= \\
& Y Z i(x, t)=\gamma^{2} i(x, t)
\end{aligned}
$$

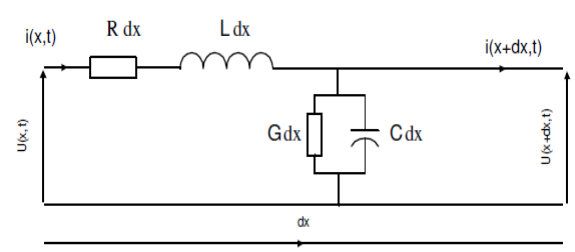

Figure 4. Single phase transmission line model.

In this equation, $\gamma$ is a complex quantity which is known as the propagation constant, and is given by

$$
\gamma=\sqrt{Z Y}=\alpha+j \beta
$$

where, $a$ is the attenuation constant which has an influence on the amplitude of the travelling wave, and $\beta$ is the phase constant which has an influence on the phase shift of the travelling wave.

Equation (7) and Equation (8) can be solved by transform or classical.

$$
\begin{aligned}
& u(x, t)=A_{1}(t) e^{\gamma x}+A_{2}(t) e^{-\gamma x} \\
& i(x, t)=-\frac{1}{Z}\left[A_{1}(t) e^{\gamma x}-A_{2}(t) e^{-\gamma x}\right]
\end{aligned}
$$

Where $Z$ is the characteristic impedance of the line and is given by

$$
Z=\sqrt{\frac{R+L \frac{\partial}{\partial t}}{G+C \frac{\partial}{\partial t}}}
$$

Where $A_{1}$ and $A_{2}$ are arbitrary functions, independent of $\mathrm{x}$.

\subsection{The Lossless Line}

Power transmission lines are normally of the three phase type. However, it is much simpler to understand travelling wave concepts and associated methods by first considering wave propagation in single phase lines. In the case of the lossless line, the series resistance $\mathrm{R}$ and the parallel conductance $\mathrm{G}$ are zero, the inductance and capacitance are constants. The transmission line equations become

$$
\begin{aligned}
& \frac{\partial u}{\partial x}=-L \frac{\partial i}{\partial t} \\
& \frac{\partial i}{\partial x}=-C \frac{\partial u}{\partial t}
\end{aligned}
$$

Since there is no damping, substituting the "steady wave" solution $\boldsymbol{u}=\boldsymbol{Z}_{\mathbf{0}} \boldsymbol{i}$ into Equations (13) and (14),

$$
\begin{gathered}
Z_{0} \frac{\partial i}{\partial x}=-L \frac{\partial i}{\partial t} \\
\frac{\partial i}{\partial x}=-Z_{0} C \frac{\partial i}{\partial t}
\end{gathered}
$$

Dividing Equation (15) by Equation (16) yields

$$
Z_{0}=\sqrt{\frac{L}{C}}
$$

This is the characteristic impedance of the lossless line. This implies that the voltage and current waves travel down the line without changing their shapes.

$$
\frac{\partial^{2} u}{\partial^{2} x^{2}}=L C u
$$

Equation (18) is the so called travellingwave equation of a loss less transmission line. The solutions of voltage and current equations reduce to

$$
\begin{gathered}
u(x, t)=A_{1}(t) e^{\frac{x}{v}}+A_{2}(t) e^{\frac{-x}{v}} \\
i(x, t)=-\frac{1}{Z_{0}}\left[A_{1}(t) e^{\frac{x}{v}}-A_{2}(t) e^{\frac{-x}{v}}\right]
\end{gathered}
$$

Where $\mathrm{v}$ is the travelling wave propagation speed defined as

$$
v=\frac{1}{\sqrt{L C}}
$$

When Taylor's series is applied to approximate a function by series,

$$
\begin{aligned}
& A(t+h)= \\
& A(t)+h A^{\prime}(t)+\left(\frac{h^{2}}{2 !}\right) A^{\prime \prime}(t)+\ldots \\
& =\left(1+h p+\frac{h^{2}}{2} p^{2}+\ldots \ldots . .\right) A(t) \\
& =e^{h p} A(t)
\end{aligned}
$$

where $p$ is the Heaviside operator

$$
p=\frac{\partial}{\partial t}
$$

Applying this to Equation (19) and Equation (20), the solutions for the voltage and current waves in the time domain can be satisfied by the general solution (also as 
showed by D'Alembert )

$$
\begin{aligned}
& u(x, t)=A_{1}\left(t+\frac{x}{v}\right)+A_{2}\left(t-\frac{x}{v}\right) \\
& i(x, t)=-\frac{1}{Z_{0}}\left[A_{1}\left(t+\frac{x}{v}\right)-A_{2}\left(t-\frac{x}{v}\right)\right]
\end{aligned}
$$

In this expression, $A_{1}\left(t+\frac{x}{v}\right)$ is a function describing a wave propagating in the negative $\mathrm{x}$ direction, usually called the backward wave, and $\boldsymbol{A}_{2}\left(\boldsymbol{t}-\frac{\boldsymbol{x}}{v}\right)$ is a function describing a wave propagating in the positive $\mathrm{x}$ direction, called the forward wave.

\subsection{Propagation Speed}

From the voltage drop equation,

$$
u(x, t)-(u+d x, t)=(L d x) \frac{\partial i(x, t)}{\partial t}
$$

Since $\boldsymbol{u}=\boldsymbol{Z}_{\mathbf{0}} \boldsymbol{i}$ then

$$
i(x, t)-i(x+d x, t)=\left(\frac{L}{Z_{0}} d x\right) \frac{\partial i(x, t)}{\partial t}
$$

Making $\frac{\partial i(x, t)}{\partial t}$ finite we get

$$
i(x, t)-i(x+d x, t)=\left(\frac{L}{Z_{0}} d x\right) \frac{i(x, t)-i(x+d x, t)}{\partial t}
$$

If the wave propagates intact

$$
v=\frac{d x}{d t}=\frac{Z_{0}}{L} v=\frac{1}{\sqrt{L C}}
$$

This is the travelling wave propagation speed.

\subsection{Reflection and Refraction of Travelling Waves}

When an electromagnetic wave propagates along a transmission line with certain characteristic impedance, there is a fixed relation between the voltage and current waves.

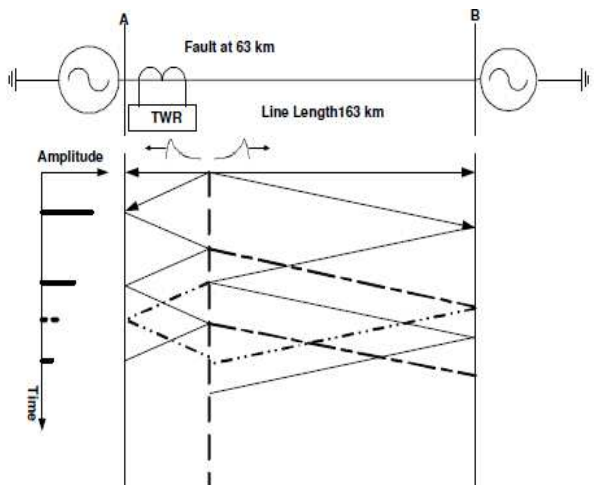

Figure 5. Lattice diagram for a fault at the first half of a transmission line.
The line is defined as

$$
\rho_{r v}=\frac{Z_{R}-Z_{0}}{Z_{R}+Z_{0}}
$$

Where $Z_{0}$ is a characteristic impedance of the line and $Z_{R}$ is the termination impedance. Similar coefficients can be obtained for the currents, but the current reflection coefficient equals the negative of the voltage reflection coefficient value.

$$
\rho_{r i}=\frac{Z_{0}-Z_{R}}{Z_{0}+Z_{R}}
$$

As a special case, termination in a short circuit results in $\boldsymbol{\rho}_{r}=\mathbf{- 1}$ for the voltage signals and $\boldsymbol{\rho}_{r i}=\mathbf{1}$ for current signals. If the termination is an open circuit, $Z_{R}$ is infinite and $\rho_{r}=\mathbf{1}$ in the limit for the voltage signal and $\boldsymbol{\rho}_{r i}=\mathbf{- 1}$ for the current signal.

For a travelling wave while propagating through the termination, the transmission (refraction) coefficient can be calculated as

$$
\rho_{t}=\frac{2 Z_{R}}{Z_{R}+Z_{0}}=\rho_{r}+1
$$

Therefore, for a line terminated in a short circuit, the voltage of the backward (or reflected) wave is equal and opposite to the voltage of the forward (or incident) wave.

\subsection{Modal Analysis}

Three phase lines have significant electromagnetic coupling between conductors. By means of modal decomposition, the coupled voltages and currents are decomposed into a new set of modal voltages and currents.For this purpose, the basic equations for a single conductor were described in Section 5.2. Here, the introduced analysis is expanded to cover the poly phase lines. Modal transformation is essentially characterized by the ability to decompose a certain group of coupled equations into decoupled ones excluding the mutual parts among these equations. This can be typically applied to the impedance matrices for coupled conductors as shown in Figure 5.3, where $\boldsymbol{Z}_{\boldsymbol{s}}$ is the self impedance, $\boldsymbol{Z}_{\boldsymbol{m}}$ is the mutual impedance, $\boldsymbol{Z}_{\boldsymbol{m}}$ are modal surge impedances for ground mode and two aerial modes (i $=0,1$ and 2). Three of the constant modal transformation matrices for perfectly transposed lines are the Clarke, Wedepohl, and Karrenbauer transformations.

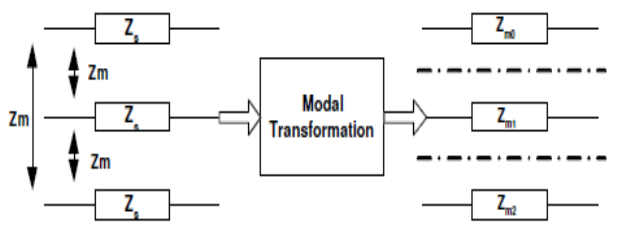




$$
\begin{aligned}
& {\left[\begin{array}{lcc}
Z_{s} & Z_{m} & Z_{m} \\
Z_{m} & Z_{s} & Z_{m} \\
Z_{m} & Z_{m} & Z_{s}
\end{array}\right] \Rightarrow} \\
& {\left[\begin{array}{ccc}
Z_{m_{0}} & \mathbf{0} & \mathbf{0} \\
& Z_{m_{1}} & \mathbf{0} \\
\mathbf{0} & \mathbf{0} & Z_{m_{2}}
\end{array}\right]}
\end{aligned}
$$

Figure 6. Modal transformation decoupling.

The modal components can be obtained by

$$
\begin{gathered}
U_{m}=T_{u}^{-1} \times U_{p} \\
I_{m}=T_{i}^{-1} \times I_{p}
\end{gathered}
$$

Where $\mathrm{U}$ and I are the phase voltage and current components and the indices $m$ and $p$ are related to modal and phase quantities, respectively. $\boldsymbol{T}_{\boldsymbol{u}}$ and $\boldsymbol{T}_{\boldsymbol{i}}$ are the corresponding voltage and current transformation matrices. Thus, the modal impedance matrix $\boldsymbol{Z}_{\boldsymbol{m}}$ can be found as

$$
Z_{m}=T_{u}^{-1} \times Z \times T_{i}
$$

For transposed lines, the transient current signals $\boldsymbol{I}_{\boldsymbol{a}}, \boldsymbol{I}_{\boldsymbol{b}}$ and $\boldsymbol{I}_{\boldsymbol{c}}$ are transformed into their modal components using Clarke's transformation as follows

$$
\left[\begin{array}{l}
I_{0} \\
I_{1} \\
I_{2}
\end{array}\right]=\frac{1}{3}\left[\begin{array}{ccc}
1 & 1 & 1 \\
2 & -1 & -1 \\
0 & \sqrt{3} & -\sqrt{3}
\end{array}\right]\left[\begin{array}{c}
I_{a} \\
I_{b} \\
I_{c}
\end{array}\right]
$$

Where $\boldsymbol{I}_{\mathbf{0}}$ is the ground mode current component, and $I_{1}$ and $I_{2}$ are known as the aerial mode current components for transposed lines. The ground mode current components $\boldsymbol{I}_{\mathbf{0}}$ are defined as zero sequence components of the symmetrical component system. The aerial mode current components $\boldsymbol{I}_{1}$ own in phase a and one half returns in phase $\mathrm{b}$ and one half in phase c. $\boldsymbol{I}_{\mathbf{2}}$ aerial mode current components are circulating in phases $\mathrm{b}$ and $\mathrm{c}$.

\subsection{Characteristics of the Travelling Wave Transients (Twt)}

A fault occurring on a transmission line will generate both voltage and current travelling waves. These will travel along the line until they meet a discontinuity on the line, such as fault point and bus bar. At this point, both a reflection and a refraction of the wave will occur. This generates additional waves which will propagate through the power system.

Fig.7 shows a diagram for a solid fault on a single phase transmission line. The voltage and current travelling wave at both ends of the line ' $\mathrm{M}$ ' and ' $\mathrm{N}$ ' can be expressed as

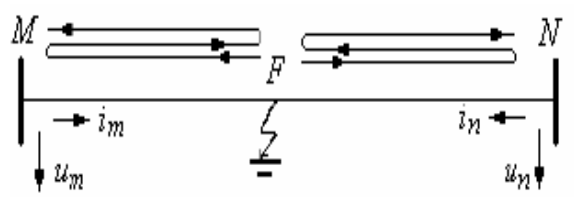

Fig. 7. Fault generated Travelling Wave on a Single Phase Transmission Line.

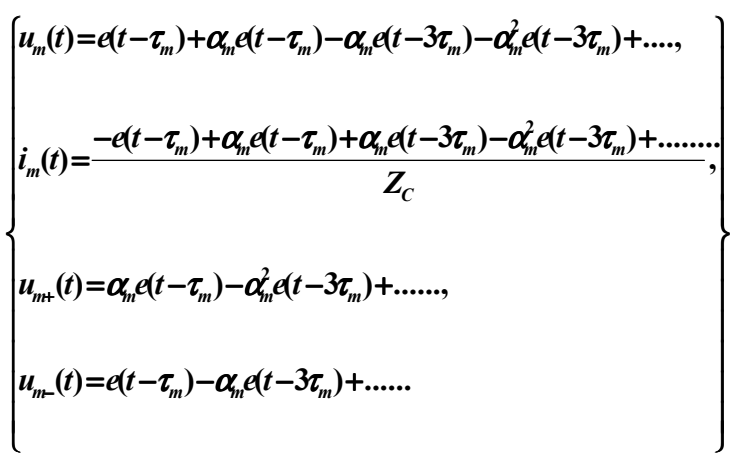

$\left\{\begin{array}{l}u_{n}(t)=e\left(t-\tau_{n}\right)+\alpha_{n} e\left(t-\tau_{n}\right)-\alpha_{n} e\left(t-3 \tau_{n}\right)-\alpha_{n}^{2} e\left(t-3 \tau_{n}\right)+\ldots ., \\ i_{n}(t)=\frac{-e\left(t-\tau_{n}\right)+\alpha_{n} e\left(t-\tau_{n}\right)+\alpha_{n} e\left(t-3 \tau_{n}\right)-\alpha_{n}^{2} e\left(t-3 \tau_{n}\right)+\ldots \ldots . .}{Z_{C}} \\ u_{n+}(t)=\alpha_{n} e\left(t-\tau_{n}\right)-\alpha_{n}^{2} e\left(t-3 \tau_{n}\right)+\ldots . ., \\ u_{n-}(t)=e\left(t-\tau_{n}\right)-\alpha_{n} e\left(t-3 \tau_{n}\right)+\ldots \ldots .\end{array}\right\}$

Where $\mathrm{m}, \mathrm{n}$ represent voltage and current quantities at end $\mathrm{M}$ and $\mathrm{N}$ respectively.

As shown in Fig. 7. and above equations, the basic characteristics of fault generated travelling wave transients can be summarized as

1) The wave characteristics change suddenly with the arrival of successive waves at the busbar. This marks the occurring of the fault and the travelling time for the journey from the fault to busbar etc.

2) The magnitude of the sudden change depends on the magnitude of the voltage at the fault instant $\mathrm{e}(\mathrm{t})$. For later waves, it also depends on the reflection and refraction coefficients at the discontinuity and the attenuation characteristics of travelling wave.

3) The polarity of the sudden change depends on the polarity of the fault voltage at the fault instant and the discontinuous characteristics of the wave impedance. Generally speaking, the polarity of travelling wave has the following characteristics

a). Reflected voltage and current waves from the fault point will have the same polarity as the incident waves.

b). The initial voltage or current waves have the same polarity at both ends of the line.

c). For the reflected positive wave from the busbar and the reflected negative wave from the fault point, their initial wave and 
reflected wave have the same polarity.

\subsection{Travelling Wave Fault Location Theory}

The voltage and current at any point $\mathrm{x}$ obey the partial differential Equations

$$
\frac{\partial e}{\partial x}=-L \frac{\partial i}{\partial t}
$$

and

$$
\frac{\partial i}{\partial x}=-C \frac{\partial e}{\partial t}
$$

Where $L$ and $C$ are the inductance and capacitance of the line per unit length. The resistance is assumed to be negligible. The solutions of these equations are

$$
\begin{gathered}
e(x, t)=e_{f}(x-v t)+e_{r}(x+v t) \\
i(x, t)=\frac{1}{Z} e_{f}(x-v t)-\frac{1}{Z} e_{r}(x+v t)
\end{gathered}
$$

where $Z=\sqrt{\frac{L}{C}}$ is the characteristic impedance of the transmission line and $v=\sqrt{\frac{1}{L C}}$ is the velocity of propagation Forward ( $\boldsymbol{e}_{\boldsymbol{f}}$ and $\boldsymbol{i}_{\boldsymbol{f}}$ ) and reverse $\left(\boldsymbol{e}_{\boldsymbol{r}}\right.$ and $\left.\boldsymbol{i}_{\boldsymbol{r}}\right)$ waves, as shown in Figure 5.8 leave the disturbed area " $x$ " travelling in different directions at " $v$ ", which is a little less than the speed of light, toward transmission line

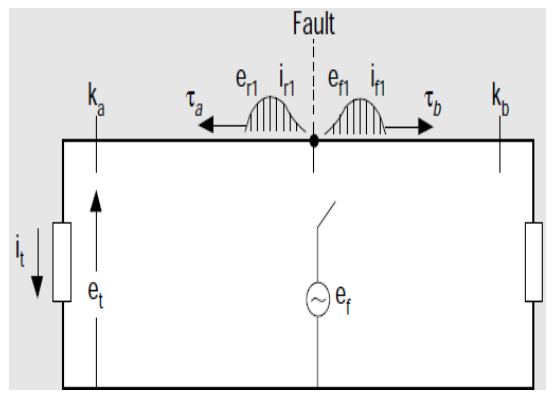

Figure 8.a. Travelling voltage and current waves ends.

The remaining energy will travel to other power system elements or transmission lines. Figure shows a Bewley lattice diagram, illustrates the multiple waves (represented by subscripts 2 and 3 ) generated at line ends. Wave amplitudes are represented by reflection coefficients ka and $\mathrm{kb}$ which are determined by characteristic impedance ratios at the discontinuities. $\tau_{\boldsymbol{a}}$ and $\boldsymbol{\tau}_{\boldsymbol{b}}$ represent the travel time from the fault to the discontinuity.

$\boldsymbol{\tau}_{\boldsymbol{a}}$ and $\boldsymbol{\tau}_{\boldsymbol{b}}$ can be determined very precisely. By knowing the length (l) of the line and the time of arrival difference ( $\boldsymbol{\tau}_{\boldsymbol{a}} \boldsymbol{\tau}_{\boldsymbol{b}}$ ), one can calculate the distance (x) to the fault from substation A by

$$
X=\frac{l-c\left(\tau_{a}-\tau_{b}\right)}{2}
$$

Where $\mathrm{c}=$ the wave propagation of $299.79 \mathrm{~m} / \mathrm{sec}$ (. $.1 \mathrm{ft} / \mathrm{ns})$

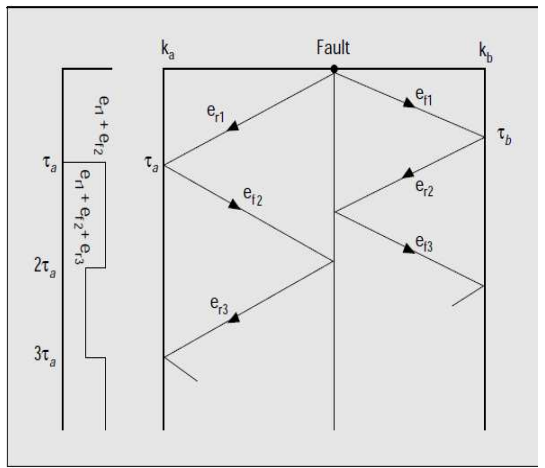

Figure 8. b. Bewley Lattice Diagram

\section{Wavelet Analysis}

\subsection{Introduction}

Most of the signals in practice are TIME DOMAIN signals. But in many applications, the most distinguished information is hidden in the frequency content of the signal. Some times both frequency and time related information may be required. In such cases various mathematical transforms are used.

\subsection{Need for Wavelet Analysis}

\subsubsection{Fourier Analysis}

Fourier analysis is the analysis, which breaks down a signal into constituent sinusoids of different frequencies and infinite duration. Another way to think of Fourier analysis is as a mathematical technique for transforming our view of the signal from time based to frequency based.
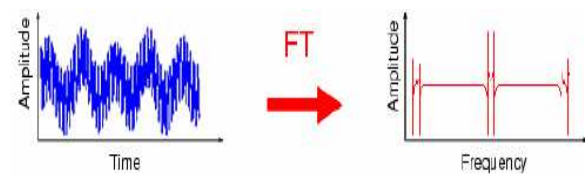

Fig. 6.2.1. Fourier analysis.
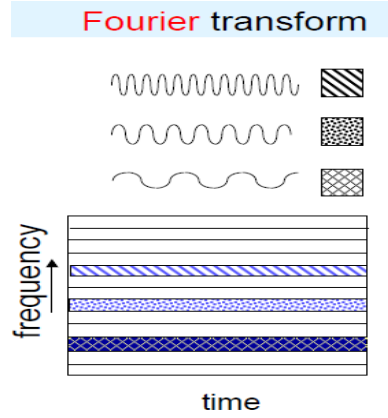

For many signals, Fourier analysis is extremely useful because the signal's frequency content is of great importance.

\subsubsection{Short Time Fourier Analysis}


In an effort to correct the deficiency of FT, Dennis Gabor (1946) adapted the Fourier transform to analyze only a small section of the signal at a time a technique called windowing the signal. Gabor's adaptation, called the Short Time Fourier Transform (STFT), maps a signal into a two dimensional function of time and frequency.

There is only a minor difference between STFT and FT. In STFT, the signal is divided into small enough segments, where these segments (portions) of the signal can be assumed to be stationary. For this purpose, a window function " $w$ " is chosen. The width of this window must be equal to the segment of the signal where its stationary is valid.
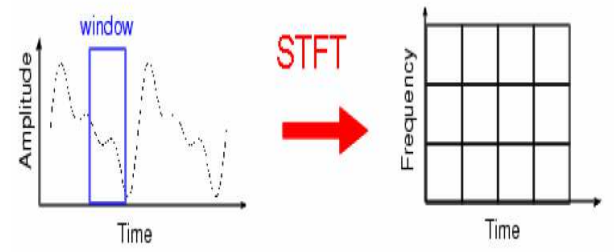

Fig. 6.2.2. Short Time Fourier analysis.

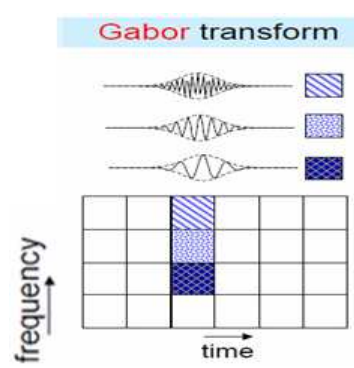

The STFT represents a sort of compromise between the time and frequency based views of a signal. It provides some information about both when and at what frequencies a signal event occurs. However, we can only obtain this information with limited precision, and that precision is determined by the size of the window.

\subsection{Wavelet Analysis}

Wavelet analysis represents the next logical step a windowing technique with variable sized regions. Wavelet analysis allows the use of long time intervals where we want more precise low frequency information, and shorter regions where we want high frequency information. Wavelet analysis does not use a time frequency region, but rather a time scale region.
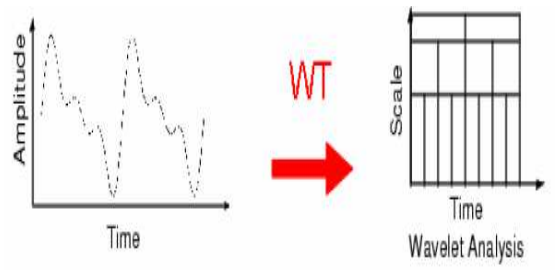

Fig. 6.3. Wavelet Analysis.

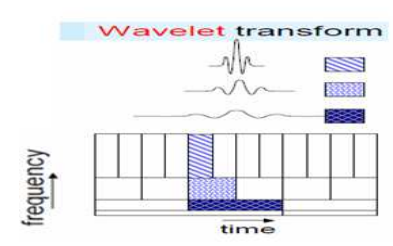

\subsubsection{Definition of Wavelet}

A wavelet is a waveform of effectively limited duration that has an average value of zero. Compared to sine waves, the basis of Fourier analysis, which do not have limited duration (they extend from minus to plus infinity) and are smooth and predictable, wavelets tend to be irregular and asymmetric.

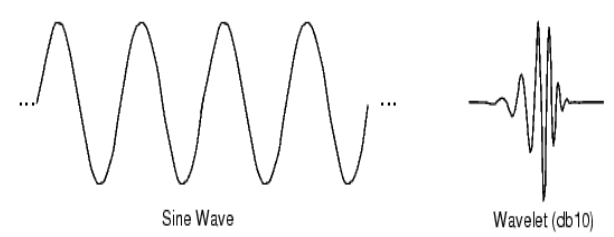

Fig. 6.3.1. Sine Wave and a Wavelet wave.

\subsubsection{Wavelet Properties}

The most important properties of wavelets are

1. The wavelet must be oscillatory.

2. It must decay quickly to zero can only be non zero for a short period of the wavelet function

3. The average value of the wavelet in the time domain must be zero,

$$
\int \psi(t) d t=0
$$

4. The wavelet function should have finite energy.

$$
\int_{-\infty}^{\infty}\left|\psi \quad(t)^{2}\right| d t<\infty
$$

5. The admissibility condition square integrable functions $\Psi(\mathrm{t})$ satisfying the Admissibility condition.

$$
c \psi=2 \pi \int_{-\infty}^{\infty}\left(|\psi(\omega)|^{2} /|\omega|\right) d \omega<\infty
$$

Can be used to first analyze and then reconstruct a signal without loss of information. In eq3.3 $\psi(\omega)$ stands for the Fourier transform of $\psi(t)$. The admissibility condition implies that the Fourier transform of $(t)$ vanishes at the zero frequency, i.e.

$$
|\psi(\omega)| 2 \mid \omega=0=0
$$

\subsection{Wavelet Transforms}

The wavelet transform, like many other transforms consists of a pair of transforms from one domain to other domain and vice versa. In case of wavelet transforms the original domain is the time domain, while the transformed domain is the time scale domain Wavelet transforms can be 
accomplished in 2 different ways.

\subsection{The Continuous Wavelet Transform}

Mathematically, the process of Fourier analysis is represented by the Fourier transform

$$
F(\omega)=\int_{-\infty}^{\infty} f(t) e^{-j \omega t} d t
$$

Which is the sum over all time of the signal $\mathrm{f}(\mathrm{t})$ multiplied by a complex exponential. Next this complex exponential can be broken down into real and imaginary sinusoidal components.

The results of the transform are the Fourier coefficients, which when multiplied by a sinusoid of frequency $\omega$, yield the constituent sinusoidal components of the original signal. Graphically, the process looks like shown in Figure below

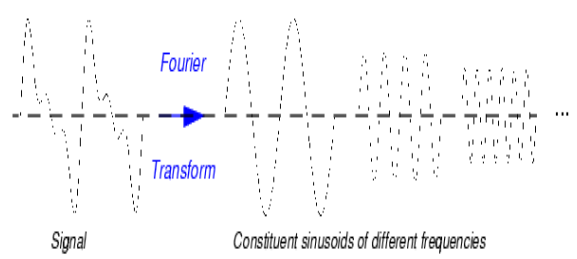

Fig. 6.5(a) Breaking the signal into sine waves of different amplitudes using FT.

Similarly, the continuous wavelet transform (CWT) is defined as the sum over all time of the signal multiplied by scaled, shifted versions of the wavelet function. The results of the CWT are many wavelet coefficients C, which are a function of scale and position.

Multiplying each coefficient by the appropriately scaled and shifted wavelet yields the constituent wavelets of the original signal

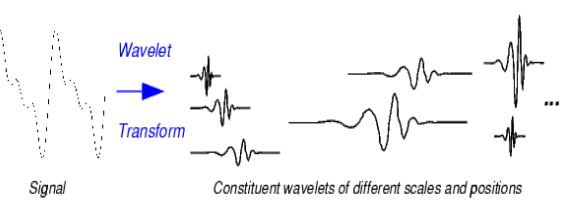

Fig. 6.5(b) Breaking the signal into wavelets of different amplitudes using WT.

Mathematically CWT is given by

Where

$$
\begin{aligned}
& C W T(a, b)=\int_{-\infty}^{\infty} x(t) \psi * a, b(t) d t \\
& \psi_{a, b}(t)=\psi((t-b) / a) \sqrt{a}
\end{aligned}
$$

$\Psi(\mathrm{t})$ is the base function or the mother wavelet, the asterisk denotes a complex conjugate, and $\mathrm{a}, \mathrm{b} \in \mathrm{R}, \mathrm{a} \neq 0$, are the dilation and translation parameters respectively

\subsubsection{Scaling}

Wavelet analysis produces a time scale view of a signal.
Scaling a wavelet simply means stretching (or compressing) it. The scale factor, often denoted by the letter $a$. for example, the effect of the scale factor with wavelets is, the smaller the scale factor, the more" compressed" the wavelet.

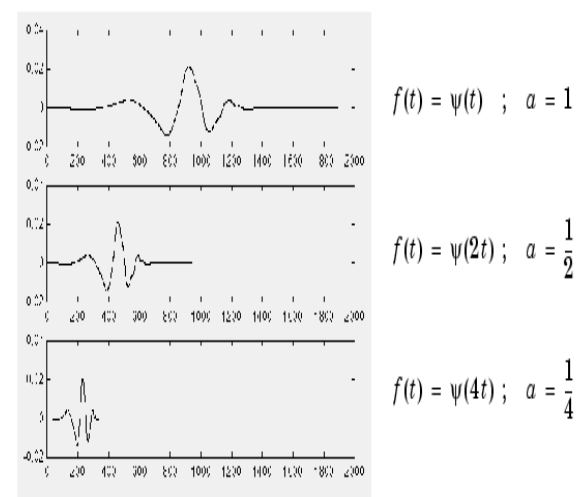

Fig. 6.5.1. Wavelets of different scales.

\subsubsection{Shifting}

Shifting a wavelet simply means delaying (or hastening) its onset. Mathematically, delaying a function $\Psi(\mathrm{t})$ by $\mathrm{k}$ is represented by $\Psi(\mathrm{t} \mathrm{k})$ and is shown in Fig6.5.2.

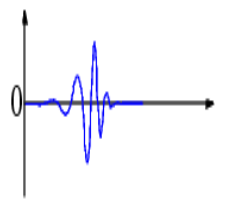

Waveletfunction $\psi(t)$

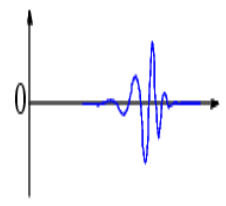

Shifted wavelet function $\psi(t-k)$
Fig. 6.5.2. delaying a wavelet function by $k$.

\subsubsection{Scale and Frequency}

The higher scales correspond to the most "stretched" wavelets. The more stretched the wavelet, the longer the portion of the signal with which it is being compared, and thus the coarser the signal features being measured by the wavelet coefficients.

Thus, there is a correspondence between wavelet scales and frequency as revealed by wavelet analysis

- Low scale a $\Rightarrow$ Compressed wavelet $\Rightarrow$ Rapidly changing detalls $\Rightarrow$ High frequency

- High scale a $\Rightarrow$ Stretched wavelet $\Rightarrow$ Slowly changing, coarse features $\Rightarrow$ Low frequency

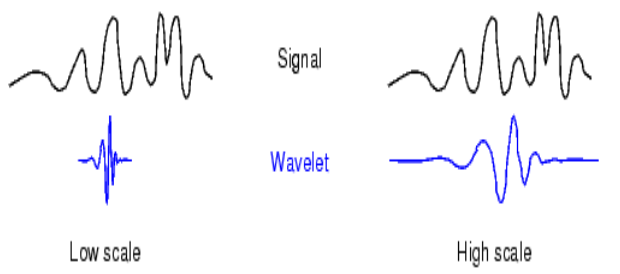

Fig. 6.5.3. Relation between scale and frequency of the signal. 


\subsection{The Discrete Wavelet Transform (DWT)}

\subsubsection{Need for Discrete Wavelet Transform}

Although the discretized continuous wavelets transform enables the computation of the continuous wavelet transforms by computers, it is not a true discrete transform.

The DWT is considerably easier to implement when compared to the CWT. the basic concepts of the DWT will be introduced in this section along with its properties and the algorithms used to compute it.

\subsubsection{The Discrete Wavelet Transforms (DWT)}

The foundations of the DWT go back to 1976 when croiser, esteban, and galand devised a technique to decompose discrete time signals. Crochiere, Weber, and Flanagan did a similar work on coding of speech signals in the same year. They named their analysis scheme as sub band coding. .And the discrete wavelet transform is given by

$$
\begin{aligned}
& D W T(m, n)= \\
& \left(\sum_{k} x[k] \psi *\left(k-n a_{0} m b_{0} / a_{0} m\right) a_{0}-m / 2\right.
\end{aligned}
$$

By comparing the eq (6.8) with general equation for impulse response (FIR) digital filter

$$
y(n)=\sum_{k} x[k] h[n-k] / c
$$

It can be seen that $\Psi(\mathrm{k})$ is the impulse response of Low pass digital filter with transfer function $\Psi(\omega)$. For $\mathrm{a}_{0}=2$, each dilation of $\Psi(\mathrm{k})$ effectively halves the bandwidth of $\Psi(\omega)$. Multilevel DWT filter banks implement the DWT eqn (6.9) in the forward transform stage and the IDWT in the reverse transform stage.

By careful selection of $a_{0}$ and $b_{0}$, the family of dilated mother wavelets constitutes an orthonormal basis of $\mathrm{L}^{2}(\mathrm{R})$.

\subsection{Filter Bank}

A time scale representation of a digital signal is obtained using digital filtering techniques. The DWT analyzes the signal at different frequency bands with different resolutions by decomposing the signal into a coarse approximation and detail information. Their sum is the DWT.

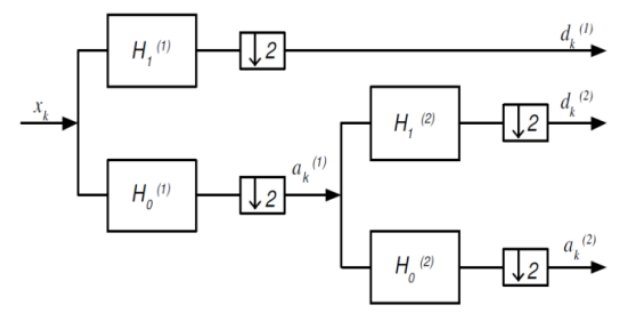

Figure 6.7. Wavelet transform filter bank.

\subsection{Daubechies Wavelets}

General characteristics Compactly supported wavelets with external phase and highest

Number of vanishing moments for a given support width .Associated scaling filters are minimum - phase filters

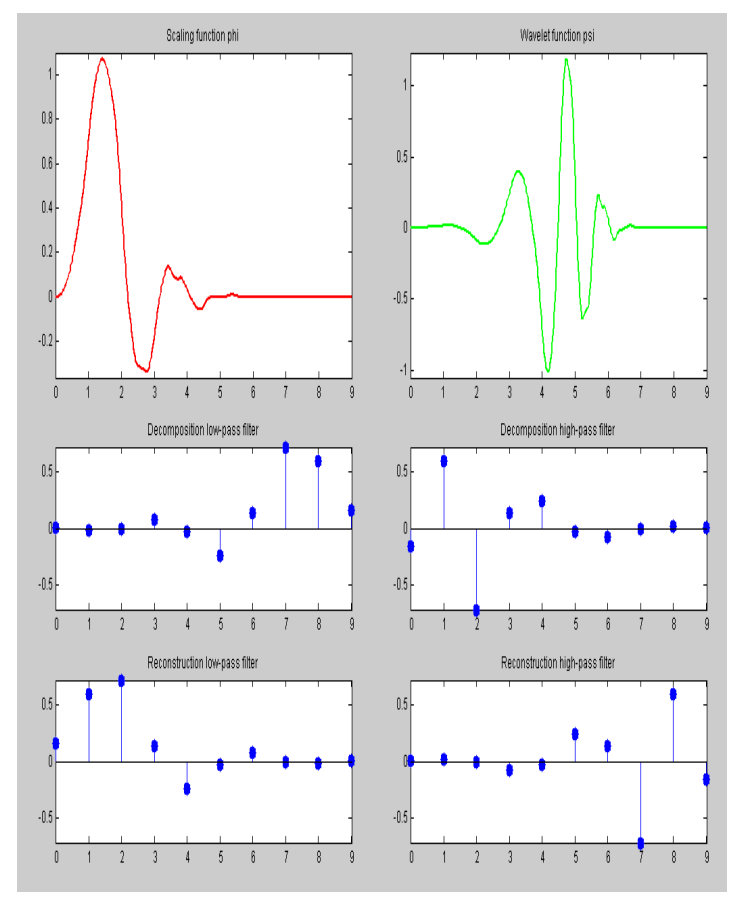

Fig. 6.8. Daubechies Wavelets(db5).

\section{Simulation Tests \&Results}

Localisation of fault using Travelling wave theory

A Transmission line model system shown in the Figure 7.1 has simulated by using MATLAB/SIM POWER SYSTEMS. The transmission line was represented as a $200 \mathrm{~km}$ long, $500 \mathrm{kv}$ ideally transposed transmission line, connecting to a load.

Fault location is done two different conFigurations

1. Single End method

2. Multi End method

\subsection{Fault Location Using Single end Method}

The electrical characteristics of a transmission line depend primarily on the construction oh the line. The values of inductance and capacitance depend on the various physical factors.

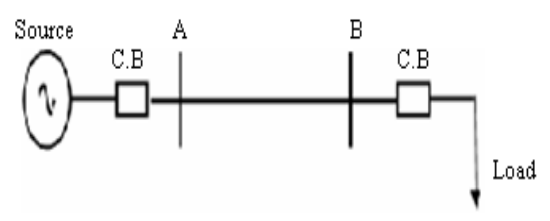

Fig. 7.1. single line diagram of transmission line model system.

\subsection{Simulation Tests \&Results}

Tests are carried out for symmetrical and unsymmetrical faults which are simulated at different distances like $200 \mathrm{Km}, 500 \mathrm{Km}, 700 \mathrm{Km}$ of transmission line and the fault 
localisation estimated using Travelling Wave Theory.

Difference in Time $=t_{2}-t_{1}$

$$
V=\frac{1}{\sqrt{L C}}
$$

is the velocity of propagation.

Distance $=$ Velocity $*$ Time

$\%$ Error between the actual and obtained distances is calculated as

(Calculated distance - actual distance )*100

actual distance

The various faults considered are

1. Line to ground (L G) fault,

2. Double line (L L) fault,

3. Double line to ground (L L G) fault,

4. $3 \Phi($ or L L L) fault, and

5. $3 \Phi$ to ground (or L L L G) fault.

Tables $1,2 \& 3$ shows the calculated fault distances by using TWT

Table 1. Location of Faults using single end method for a 200Km Transmission line.

\begin{tabular}{|l|l|l|l|l|l|l|l|l|}
\hline \multicolumn{2}{|c|}{ Fault } & \multicolumn{2}{|c|}{ L-G } & \multicolumn{2}{c|}{ L-L } & \multicolumn{2}{c|}{ L-L-G } & \multicolumn{2}{l|}{ LLL/LLLG } \\
\hline $\begin{array}{l}\text { Distance } \\
(\mathrm{km})\end{array}$ & $\begin{array}{l}\text { Calculated } \\
\text { Distance } \\
(\mathrm{km})\end{array}$ & \%error & $\begin{array}{l}\text { Calculated } \\
\text { Distance } \\
(\mathrm{km})\end{array}$ & $\begin{array}{l}\text { \%error } \\
\text { Calculated } \\
\text { Distance } \\
(\mathrm{km})\end{array}$ & $\begin{array}{l}\text { \%error } \\
\text { Calculated } \\
\text { Distance } \\
(\mathrm{km})\end{array}$ & \%error \\
\hline 25 & 24.19 & -3.34 & 24.19 & -3.34 & 24.19 & -3.34 & 24.19 & -3.34 \\
\hline 50 & 48.32 & -3.34 & 48.32 & -3.34 & 48.32 & -3.34 & 48.32 & -3.34 \\
\hline 75 & 72.48 & -3.34 & 72.48 & -3.34 & 72.48 & -3.34 & 72.48 & -3.34 \\
\hline 100 & 96.69 & -3.35 & 96.69 & -3.35 & 96.69 & -3.35 & 96.69 & -3.35 \\
\hline 125 & 120.80 & -3.35 & 120.80 & -3.35 & 120.80 & -3.35 & 120.80 & -3.35 \\
\hline 150 & 144.97 & -3.34 & 144.97 & -3.34 & 144.97 & -3.34 & 144.97 & -3.34 \\
\hline 175 & 169.12 & -3.35 & 169.12 & -3.35 & 169.12 & -3.35 & 169.12 & -3.35 \\
\hline 200 & 193.30 & -3.34 & 193.30 & -3.34 & 193.30 & -3.34 & 193.30 & -3.34 \\
\hline
\end{tabular}

Table 2. Location of Faults using single end method for a for a $500 \mathrm{Km}$ Transmission line.

\begin{tabular}{|c|c|c|c|c|c|c|c|c|}
\hline \multirow{2}{*}{$\begin{array}{l}\text { Fault } \\
\rightarrow \\
\text { Distance } \\
(\mathrm{kmin})\end{array}$} & \multicolumn{2}{|c|}{ L.G } & \multicolumn{2}{|c|}{ L.L } & \multicolumn{2}{|c|}{ L.L.G } & \multicolumn{2}{|c|}{ | LLLLLLG } \\
\hline & \begin{tabular}{|l|} 
Calculated \\
Distance \\
(kin) \\
\end{tabular} & Q/fervor & \begin{tabular}{|l|} 
Calculated \\
Distance \\
(kmit) \\
\end{tabular} & & $\begin{array}{l}\text { Calculated } \\
\text { Distance } \\
\text { (kmin) }\end{array}$ & 9oerror & $\begin{array}{l}\text { Calculated } \\
\text { pistance } \\
\text { (kmil) }\end{array}$ & \%error \\
\hline 100 & 96.65 & -3.35 & 96.65 & -3.35 & 96.65 & -3.35 & 96.65 & -3.35 \\
\hline 200 & 193.30 & -3.35 & 193.30 & -3.35 & 19330 & -3.35 & 193.30 & -3.35 \\
\hline 300 & 289.85 & -3.35 & 289.85 & -3.35 & 289.85 & -3.35 & 289.85 & -3.35 \\
\hline 400 & 386.61 & -3.34 & 386.61 & -3.34 & 3866.61 & -3.34 & 386.61 & -3.34 \\
\hline 500 & 483.23 & -3.34 & 483.23 & -3.34 & 483.23 & -3.34 & 483.23 & -3.34 \\
\hline
\end{tabular}

Table 3. Location of Faults using single end method for a for a $700 \mathrm{Km}$ Transmission line.

\begin{tabular}{|c|c|c|c|c|c|c|c|c|}
\hline Fault & \multicolumn{2}{|c|}{ L-G } & \multicolumn{2}{|c|}{ L-L } & \multicolumn{2}{|c|}{ L-L-G } & \multicolumn{2}{|c|}{ LLL/LLLG } \\
\hline $\begin{array}{l}\text { Distance } \\
(\mathrm{km})\end{array}$ & $\begin{array}{l}\text { Calculated } \\
\text { Distance } \\
\text { (km) } \\
\end{array}$ & \%error & $\begin{array}{l}\text { Calculated } \\
\text { Distance } \\
\text { (kmi) }\end{array}$ & \%error & $\begin{array}{l}\text { Calculated } \\
\text { Distance } \\
\text { (km) }\end{array}$ & \%error & $\begin{array}{l}\text { Calculated } \\
\text { Distance } \\
\text { (km) }\end{array}$ & \%error \\
\hline 100 & 96.65 & -3.35 & 96.65 & -3.35 & 96.65 & \begin{tabular}{|l|}
-3.35 \\
\end{tabular} & 96.65 & -3.35 \\
\hline 200 & 193.30 & -3.35 & 193.30 & \begin{tabular}{|l|}
-3.35 \\
\end{tabular} & 193.30 & \begin{tabular}{|l|}
-3.35 \\
\end{tabular} & 193.30 & -3.35 \\
\hline 300 & 289.85 & -3.35 & 289.85 & \begin{tabular}{|l|}
-3.35 \\
\end{tabular} & 289.85 & \begin{tabular}{|l|}
-3.35 \\
\end{tabular} & 289.85 & -3.35 \\
\hline 400 & 386.61 & -3.34 & 386.61 & \begin{tabular}{|l|}
-3.34 \\
\end{tabular} & 386.61 & \begin{tabular}{|l|}
-3.34 \\
\end{tabular} & 386.61 & -3.34 \\
\hline 500 & 483.23 & -3.34 & 483.23 & \begin{tabular}{|l|}
-3.34 \\
\end{tabular} & 483.23 & -3.34 & 483.23 & -3.34 \\
\hline 600 & 579.88 & -3.35 & 579.88 & -3.35 & 579.88 & \begin{tabular}{|l|}
-3.35 \\
\end{tabular} & 579.88 & -3.35 \\
\hline 700 & 676.53 & -3.35 & 676.53 & -3.35 & 676.53 & -3.35 & 676.53 & -3.35 \\
\hline
\end{tabular}

\subsubsection{Case I. Specifications of a $200 \mathrm{Km}$ Transmission}

Line

Source Voltage $500 \mathrm{kV}, 50 \mathrm{~Hz}$

Transmission Line Length $200 \mathrm{Km}$, distributed parameter transmission line model

$$
\begin{gathered}
\mathrm{R} 1=0.01273 \Omega / \mathrm{km} ; \mathrm{R} 0=0.3864 \Omega / \mathrm{km} ; \\
\mathrm{L} 1=0.9337 \mathrm{e} 3 \mathrm{H} / \mathrm{km} ; \mathrm{L} 0=4.1264 \mathrm{e} 3 \mathrm{H} / \mathrm{km} ; \\
\mathrm{C} 1=12.74 \mathrm{e} 9 \mathrm{~F} / \mathrm{km} \mathrm{C} 0=7.751 \mathrm{e} 9 \mathrm{~F} / \mathrm{km}
\end{gathered}
$$

Fault is created at 0.0006 and cleared at 0.0009 , simulation time 0.0015

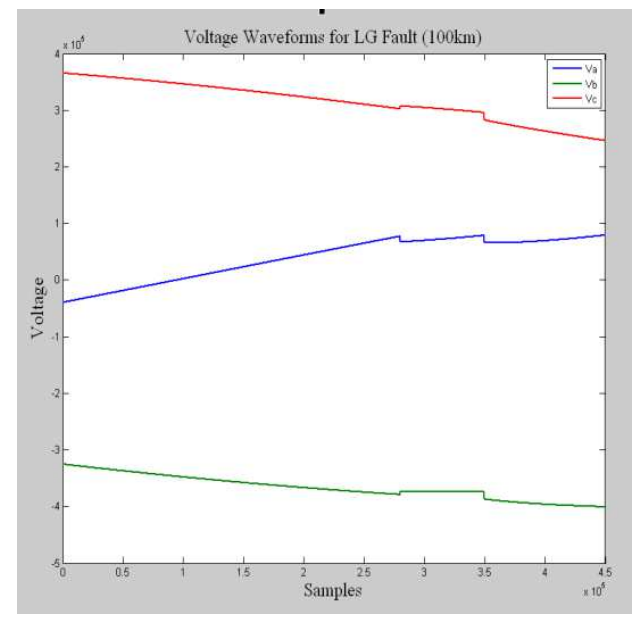

Fig. 7.2.1(b) Voltage wave form, for $L \mathrm{G}$ fault at $100 \mathrm{~km}$.

The voltage waveform in Figrepresents an $L$ G fault created at distance of $100 \mathrm{~km}$ on a transmission line of $200 \mathrm{~km}$ long, the fault creation time is $0.0006 \mathrm{sec}$ and the shift in voltage wave form appears at $0.000934 \mathrm{sec}$ this is due to the travelling time taken by the fault to appear at the relay point.

\subsubsection{Case II. Specifications of A $500 \mathrm{Km}$ Length Line with Distributed Parameters}

Source Voltage $500 \mathrm{kV}, 50 \mathrm{~Hz}$

Transmission Line Length $500 \mathrm{Km}$, distributed parameter transmission line model 


$$
\begin{gathered}
\mathrm{R} 1=0.01273 \Omega / \mathrm{km} ; \mathrm{R} 0=0.3864 \Omega / \mathrm{km} ; \\
\mathrm{L} 1=0.9337 \mathrm{e} 3 \mathrm{H} / \mathrm{km} ; \mathrm{L} 0=4.1264 \mathrm{e} 3 \mathrm{H} / \mathrm{km} ; \\
\mathrm{C} 1=12.74 \mathrm{e} 9 \mathrm{~F} / \mathrm{km} \mathrm{C} 0=7.751 \mathrm{e} 9 \mathrm{~F} / \mathrm{km}
\end{gathered}
$$

Fault is created at 0.003 and cleared at 0.004 , simulation time 0.005

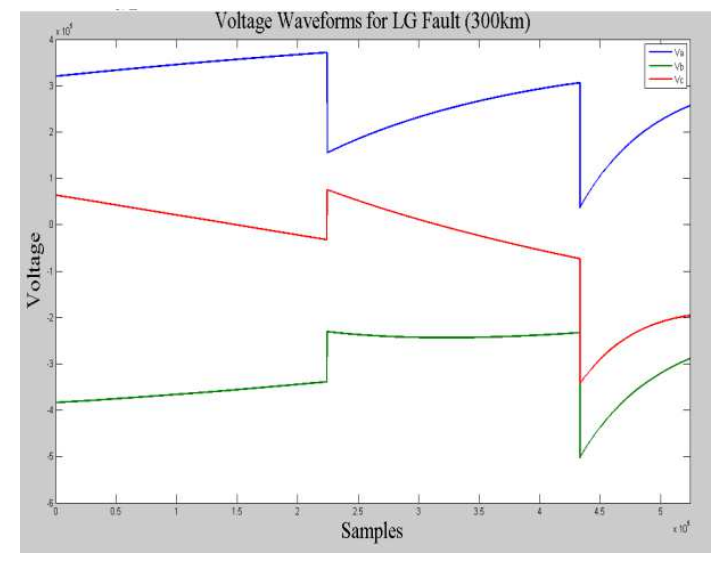

Fig. 7.2.2(a) Voltage wave form, for LG fault at $300 \mathrm{Km}$.

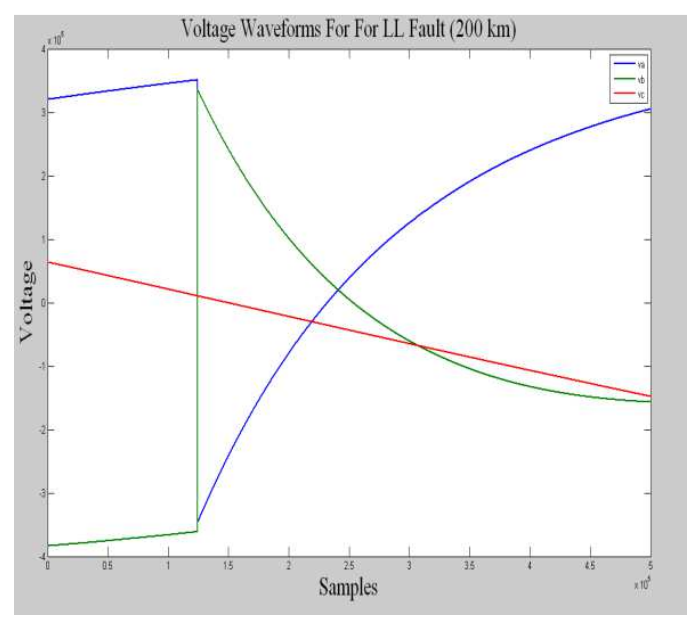

Fig. 7.2.2(b) Voltage wave form, for LL fault at 200Km.

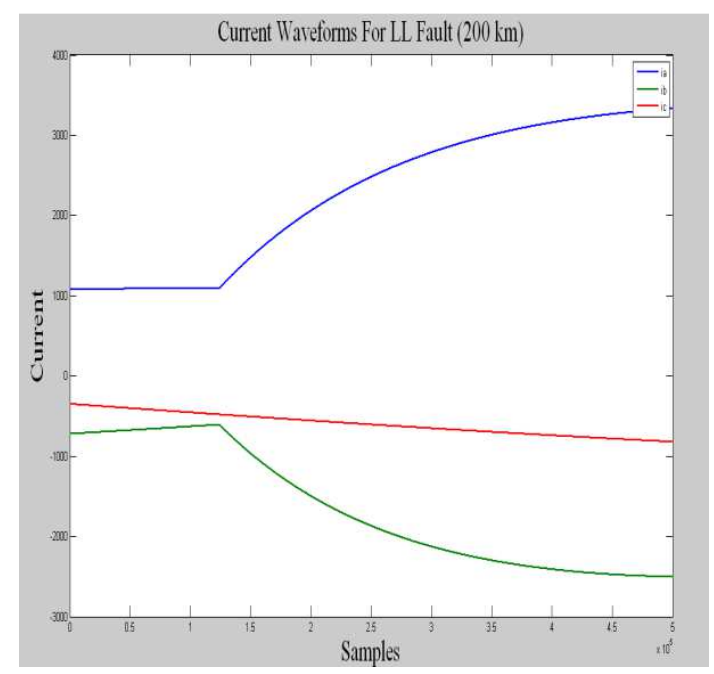

Fig. 7.2.2(c) Current wave form, for LL fault at $200 \mathrm{Km}$.

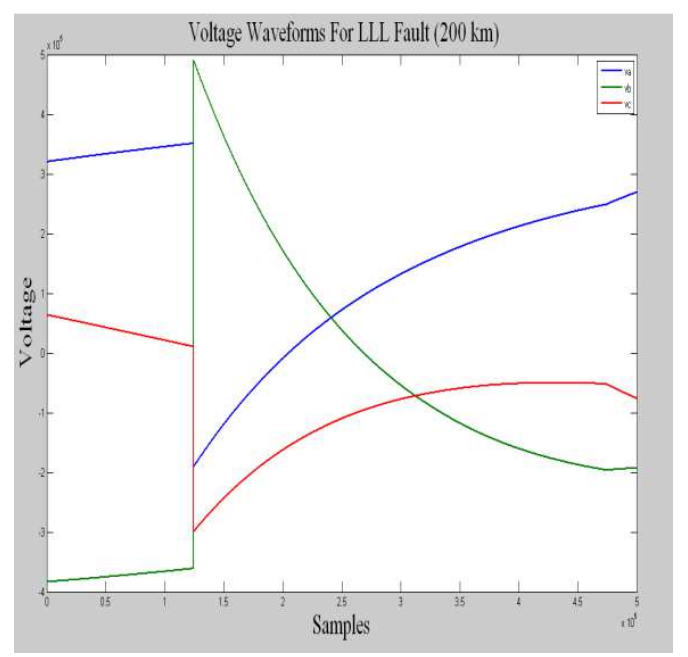

Fig. 7.2.2(d) Voltage wave form, for LLL fault at $200 \mathrm{Km}$.

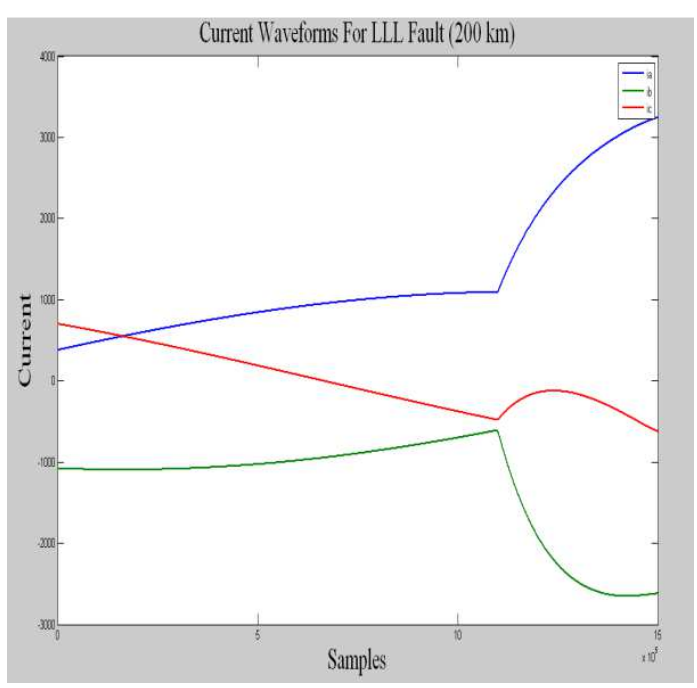

Fig. 7.2.2 (e) Current wave form, for LLL fault at $200 \mathrm{Km}$.

The above voltage waveform represents an LG fault created at distance of $300 \mathrm{~km}$ on a transmission line of $500 \mathrm{~km}$ long, the fault creation time is $0.003 \mathrm{sec}$ and the shift in voltage wave form appears at $0.0040002 \mathrm{sec}$ this is due to the travelling time taken by the fault to appear at the relay point.

\subsubsection{Case III. Specifications of a $700 \mathrm{Km}$ Transmission Line}

Source Voltage $500 \mathrm{kV}, 50 \mathrm{~Hz}$

Transmission Line Length $700 \mathrm{Km}$, distributed parameter transmission line model

$$
\begin{gathered}
\mathrm{R} 1=0.01273 \Omega / \mathrm{km} ; \mathrm{R} 0=0.3864 \Omega / \mathrm{km} ; \\
\mathrm{L} 1=0.9337 \mathrm{e} 3 \mathrm{H} / \mathrm{km} ; \mathrm{L} 0=4.1264 \mathrm{e} 3 \mathrm{H} / \mathrm{km} ; \\
\mathrm{C} 1=12.74 \mathrm{e} 9 \mathrm{~F} / \mathrm{km} \mathrm{C} 0=7.751 \text { e } 9 \mathrm{~F} / \mathrm{km}
\end{gathered}
$$

Fault is created at $0.004 \mathrm{sec}$ and cleared at $0.005 \mathrm{sec}$, simulation time $0.0065 \mathrm{sec}$

The above voltage waveform represents an LG fault created at distance of $500 \mathrm{~km}$ on a transmission line of 
$700 \mathrm{~km}$ long, the fault creation time is $0.004 \mathrm{sec}$ and the shift in voltage wave form appears at $0.0056669 \mathrm{sec}$ this is due to the travelling time taken by the fault to appear at the relay point.

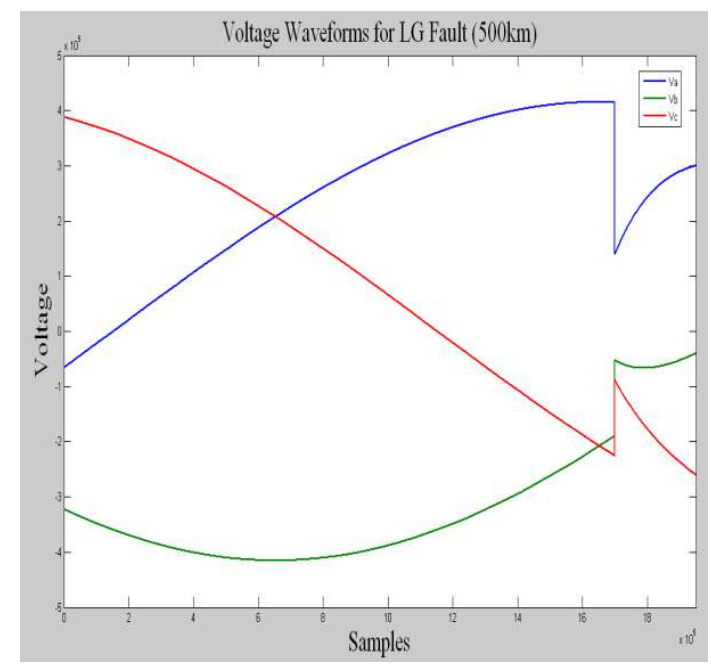

Fig. 7.2.3(a) Voltage wave form, $L$ G fault at $500 \mathrm{~km}$.

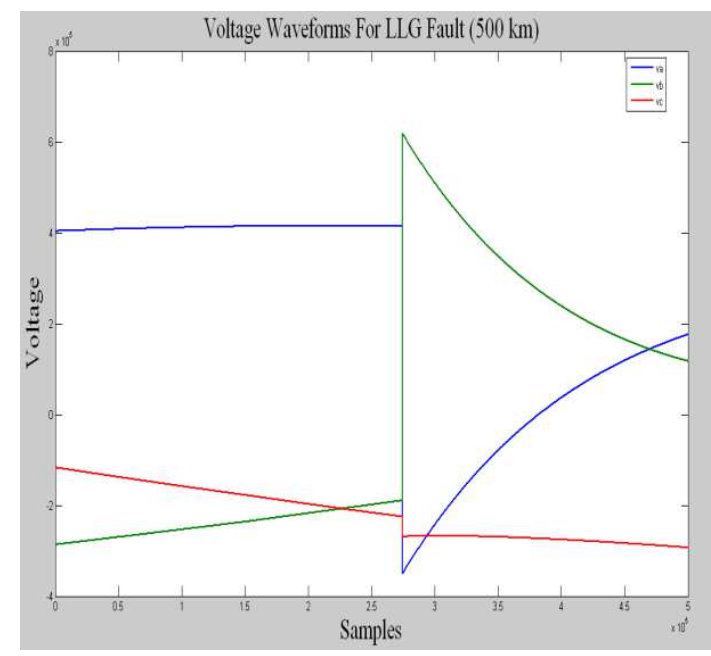

Fig. 7.2.3(b) Voltage wave form, $L L G$ fault at $500 \mathrm{~km}$.

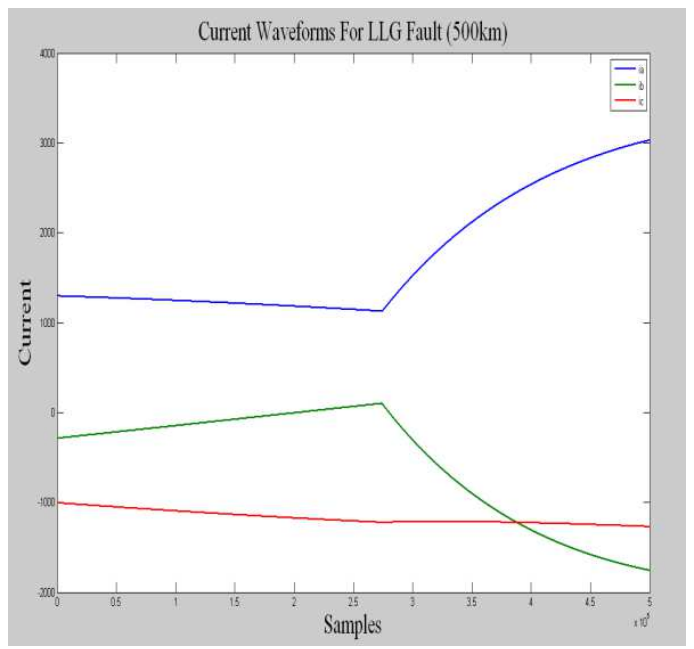

Fig. 7.2.3(c) Current wave form, $L G$ fault at $500 \mathrm{~km}$.

\subsection{Multi end Method}

Various methods and different techniques of fault location have been developed in the literature. In traveling wave based method, the fault location can be found by comparing the arrival time of the initial and reflected transient signals at a single end of the line terminals. Single ended methods show more economical advantages.

\section{Faulty Line Estimation}

The transmission line model considered for this work has been shown in Fig6.4.3

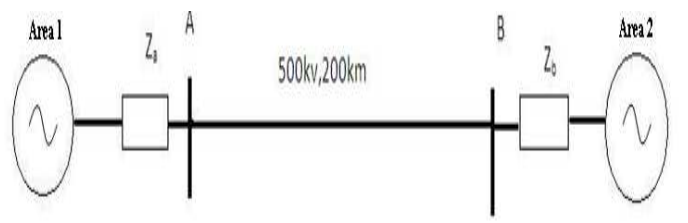

Fig. 7.3. Two Area Transmission line network.

\subsubsection{CaseI .Specifications}

Source Voltage $500 \mathrm{kV}, 50 \mathrm{~Hz}$

Transmission Line Length $200 \mathrm{Km}$, distributed parameter transmission line model

$$
\begin{gathered}
\mathrm{R} 1=0.01273 \Omega / \mathrm{km} ; \mathrm{R} 0=0.3864 \Omega / \mathrm{km} ; \\
\mathrm{L} 1=0.9337 \mathrm{e} 3 \mathrm{H} / \mathrm{km} ; \mathrm{L} 0=4.1264 \mathrm{e} 3 \mathrm{H} / \mathrm{km} ; \\
\mathrm{C} 1=12.74 \mathrm{e} 9 \mathrm{~F} / \mathrm{km} \mathrm{C} 0=7.751 \mathrm{e} 9 \mathrm{~F} / \mathrm{km}
\end{gathered}
$$

Fault is created at 0.0008 and cleared at 0.0009 , simulation time 0.0015

The above current waveform represents an LG fault created at distance of $50 \mathrm{~km}$ on a transmission line of $200 \mathrm{~km}$ long, the fault creation time is $0.0008 \mathrm{sec}$ and the shift in voltage wave form appears at $0.00097245 \mathrm{sec}$ this is due to the travelling time taken by the fault to appear at the relay point.

\section{Two Area Power System}

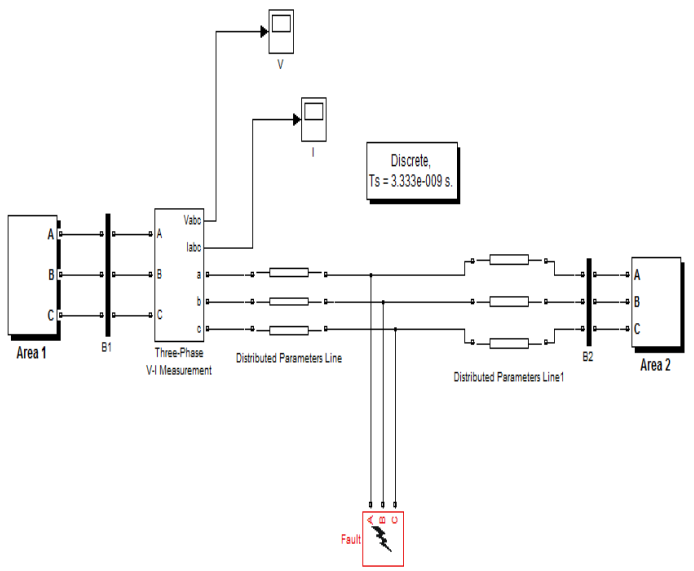

Fig.7.3.1(a) MATLAB model of the system. 


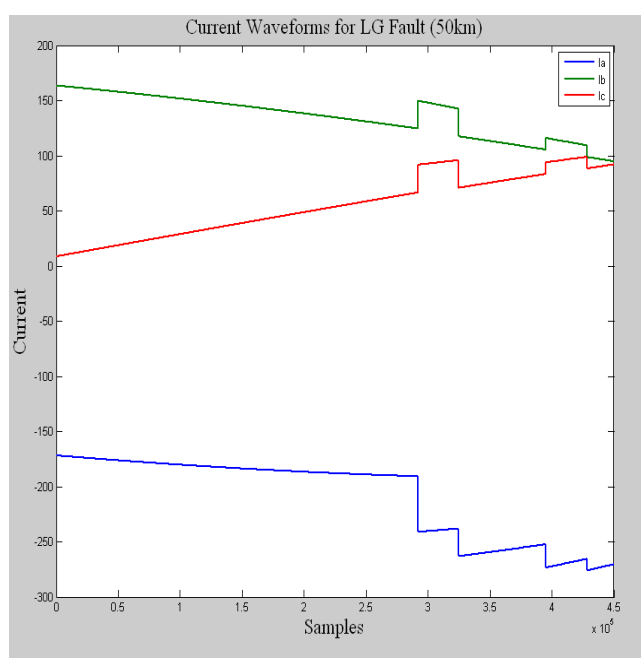

Fig. 7.3.1(b) Current wave form, $L$ G fault at $50 \mathrm{~km}$.

Fault is created at 0.0008 Seconds.

But the fault appeared at 0.00097245 Seconds.

Difference in Time $=(0.0009725-0.0008)$

$=0.0001725$ Seconds

$$
V=\frac{1}{\sqrt{L C}}
$$

is the velocity of propagation.

$$
\begin{aligned}
& V= \frac{1}{\sqrt{0.9337 * 10^{-3} * 12.74 * 10^{-9}}} \\
& V= 2.899 * 10^{5} \mathrm{Km} / \mathrm{sec} \\
& \text { Distance }=\text { Velocity } * \text { Time }
\end{aligned}
$$

Distance $=2.899 * 105 * 0.0001725$

\begin{tabular}{|c|c|c|c|c|c|c|c|c|}
\hline Fault & \multicolumn{2}{|c|}{ L-G } & \multicolumn{2}{|c|}{ L-L } & \multicolumn{2}{|l|}{ L-L.G } & \multicolumn{2}{|c|}{ LLL/LLLG } \\
\hline $\begin{array}{l}\text { Distance } \\
\text { (kmi) }\end{array}$ & $\begin{array}{l}\text { Calculated } \\
\text { Distance } \\
\text { (kmin) } \\
\end{array}$ & \%error & $\begin{array}{l}\text { Calculated } \\
\text { Distance } \\
\text { (kmin) } \\
\end{array}$ & \%error & \begin{tabular}{|l|} 
Calculated \\
Distance \\
$(\mathrm{km})$ \\
\end{tabular} & \%error & $\begin{array}{l}\text { Calculated } \\
\text { pistance } \\
\text { (km) } \\
\end{array}$ & \%error \\
\hline 25 & 24.99 & -0.01 & 24.99 & -0.01 & 24.99 & -0.01 & 24.99 & -0.01 \\
\hline 50 & 49.99 & -0.01 & 49.99 & -0.01 & 49.99 & -0.01 & 49.99 & -0.01 \\
\hline 75 & 74.99 & -0.03 & 74.99 & -0.03 & 74.99 & -0.03 & 74.99 & -0.03 \\
\hline 100 & 99.98 & -0.01 & 99.98 & -0.01 & 99.98 & -0.01 & 99.98 & -0.01 \\
\hline 125 & 124.97 & -0.01 & 124.97 & -0.01 & 124.97 & -0.01 & 124.97 & -0.01 \\
\hline 150 & 149.96 & -0.02 & 149.96 & -0.02 & 149.96 & -0.02 & 149.96 & -0.02 \\
\hline 175 & 174.98 & -0.009 & 174.98 & -0.009 & 174.98 & -0.009 & 174.98 & -0.009 \\
\hline 200 & 199.97 & -0.01 & 199.97 & -0.01 & 199.97 & -0.01 & 199.97 & -0.01 \\
\hline
\end{tabular}

$$
\text { Distance }=50.00775 \text {. }
$$

Table 4. Location of Faults using double end method for a 200Km Transmission line.

\subsubsection{CaseII. Specifications}

Source Voltage $500 \mathrm{kV}, 50 \mathrm{~Hz}$

Transmission Line Length $500 \mathrm{Km}$, distributed parameter transmission line model

$$
\begin{gathered}
\mathrm{R} 1=0.01273 \Omega / \mathrm{km} ; \mathrm{R} 0=0.3864 \Omega / \mathrm{km} ; \\
\mathrm{L} 1=0.9337 \mathrm{e} 3 \mathrm{H} / \mathrm{km} ; \mathrm{L} 0=4.1264 \mathrm{e} 3 \mathrm{H} / \mathrm{km} ; \\
\mathrm{C} 1=12.74 \mathrm{e} 9 \mathrm{~F} / \mathrm{km} \mathrm{C} 0=7.751 \mathrm{e} 9 \mathrm{~F} / \mathrm{km}
\end{gathered}
$$

Fault is created at 0.002 and cleared at 0.004 , simulation time 0.004 .

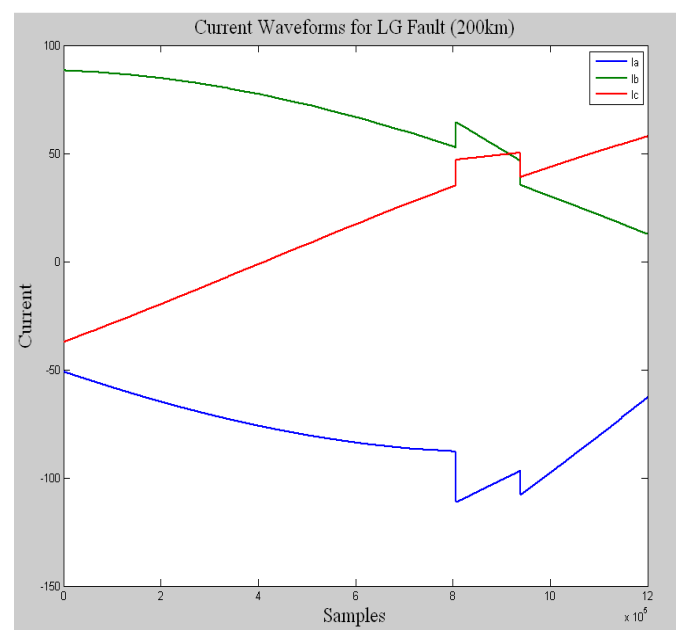

Fig. 7.3.2. Current wave form, $L$ G fault at $200 \mathrm{~km}$.

The above current waveform represents an LG fault

\begin{tabular}{|c|c|c|c|c|c|c|c|c|}
\hline & \multicolumn{2}{|c|}{$\mathrm{L} r \mathrm{G}$} & \multicolumn{2}{|l|}{$\mathrm{L}-\mathrm{L}$} & \multicolumn{2}{|c|}{ L-LG } & \multicolumn{2}{|c|}{ LLLLLG } \\
\hline $\begin{array}{l}\text { Distance } \\
\text { (kim) }\end{array}$ & \begin{tabular}{|l} 
Calculated \\
Distalce \\
(kin) \\
\end{tabular} & \%eltor & \begin{tabular}{|l} 
Calculated \\
Distanlce \\
(km) \\
\end{tabular} & 9:oerror & $\begin{array}{l}\text { Calculated } \\
\text { Distance } \\
\text { (kn) }\end{array}$ & \%elinor & $\begin{array}{l}\text { Calculated } \\
\text { Distanlce } \\
\text { (kim) }\end{array}$ & \%error \\
\hline 100 & 99.98 & -0.02 & 99.98 & -0.02 & 99.98 & -0.02 & 99,98 & -0.02 \\
\hline 200 & 199.97 & -0.015 & 199.97 & -0.015 & 199.97 & -0.015 & 199.97 & -0.015 \\
\hline 300 & 299.95 & -0.016 & 299.95 & -0.016 & 299.95 & -0.016 & 299.95 & -0.016 \\
\hline 400 & 399.94 & -0.015 & 399.94 & -0.015 & 399.94 & -0.015 & 399.94 & -0.015 \\
\hline 500 & 499.93 & -0.014 & 499.93 & -0.014 & 499.93 & -0.014 & 499.93 & -0.014 \\
\hline
\end{tabular}
created at distance of $200 \mathrm{~km}$ on a transmission line of $500 \mathrm{~km}$ long, the fault creation time is $0.002 \mathrm{sec}$ and the shift in voltage wave form appears at $0.0026898 \mathrm{sec}$ this is due to the travelling time taken by the fault to appear at the relay point.

Table 5. Location of Faults using double end method for a 500Km Transmission line.

\subsubsection{CaseIII. Specifications}

Source Voltage $500 \mathrm{kV}, 50 \mathrm{~Hz}$

Transmission Line Length $700 \mathrm{Km}$, distributed parameter transmission line model

$$
\mathrm{R} 1=0.01273 \Omega / \mathrm{km} ; \mathrm{R} 0=0.3864 \Omega / \mathrm{km} ;
$$




$$
\begin{gathered}
\mathrm{L} 1=0.9337 \mathrm{e} 3 \mathrm{H} / \mathrm{km} ; \mathrm{L} 0=4.1264 \mathrm{e} 3 \mathrm{H} / \mathrm{km} ; \\
\mathrm{C} 1=12.74 \mathrm{e} 9 \mathrm{~F} / \mathrm{km} \mathrm{C} 0=7.751 \mathrm{e} 9 \mathrm{~F} / \mathrm{km}
\end{gathered}
$$

Fault is created at 0.0028 and cleared at 0.006 simulation time 0.006

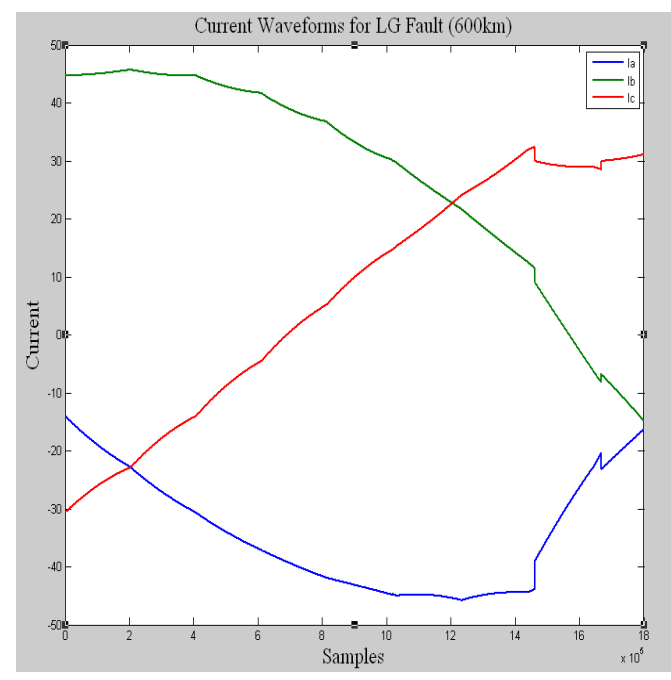

Fig. 7.3.3. Current wave form, L G fault at $600 \mathrm{~km}$.

The above current waveform represents an LG fault created at distance of $600 \mathrm{~km}$ on a transmission line of $700 \mathrm{~km}$ long, the fault creation time is $0.0028 \mathrm{sec}$ and the shift in voltage wave form appears at $0.0048694 \mathrm{sec}$ this is due to the travelling time taken by the fault to appear at the relay point.

Table 6. Location of Faults using double end method for a 700Km Trans-

\begin{tabular}{|c|c|c|c|c|c|c|c|c|}
\hline \multirow{2}{*}{$\begin{array}{l}\text { Fanlt } \\
\stackrel{\text { Distance }}{\longrightarrow} \\
\text { (lim) }\end{array}$} & \multicolumn{2}{|c|}{ L-G } & \multicolumn{2}{|c|}{$\mathrm{L}-\mathrm{L}$} & \multicolumn{2}{|c|}{ L-L-G } & \multicolumn{2}{|c|}{ LLLLLLG } \\
\hline & $\begin{array}{l}\text { Calculated } \\
\text { Distance } \\
\text { (kin) }\end{array}$ & \%error & $\begin{array}{l}\text { Calculated } \\
\text { Distance } \\
\text { (kim) }\end{array}$ & \%errior & \begin{tabular}{|l|} 
Calculated \\
Distance \\
(km) \\
\end{tabular} & \%error & \begin{tabular}{|l|} 
Calculated \\
Distance \\
(kin) \\
\end{tabular} & \%error \\
\hline 100 & 99.98 & -0.02 & 99.98 & -0.02 & 99.98 & -0.02 & 99.98 & -0.02 \\
\hline 200 & 199.97 & -0.015 & 199.97 & -0.015 & 199.97 & -0.015 & 199.97 & -0.015 \\
\hline 300 & 299.95 & -0.016 & 299.95 & -0.016 & 299.95 & -0.016 & 299,95 & -0.016 \\
\hline 400 & 399.94 & -0.015 & 399.94 & -0.015 & 399.94 & -0.015 & 399.94 & -0.015 \\
\hline 500 & 499.93 & -0.014 & 499.93 & -0.014 & 499.93 & -0.014 & 499.93 & -0.014 \\
\hline 600 & 599.91 & -0.015 & 599.91 & -0.015 & 599.91 & -0.015 & 599,91 & -0.015 \\
\hline 700 & 699.90 & -0.014 & 699.90 & -0.014 & 699.90 & -0.014 & 699.90 & -0.014 \\
\hline
\end{tabular}
mission line.

\subsection{Localisation of faults using Bewley method with wavelet transforms}

Transmission line ends represent a discontinuity or impedance change where some of the wave's energy will reflect back to the disturbance. The remaining energy will travel to other power system elements or transmission lines. Figure 7.4 a Bewley lattice diagram, illustrates the multiple waves (represented by subscripts 2 and 3 ) generated at line ends. Wave amplitudes are represented by reflection coeffi- cients $\mathrm{ka}$ and $\mathrm{kb}$ which are determined by characteristic impedance ratios at the discontinuities. $\tau_{\boldsymbol{a}}$ and $\boldsymbol{\tau}_{\boldsymbol{b}}$ represent the travel time from the fault to the discontinuity. $\boldsymbol{\tau}_{\boldsymbol{a}}$ and $\boldsymbol{\tau}_{\boldsymbol{b}}$ can be determined very precisely. By knowing the length (1) of the line and the time of arrival difference $\left(\begin{array}{ll}\tau_{a} & \tau_{b}\end{array}\right)$, one can calculate the distance (x) to the fault from substation A by

$$
X=\frac{l-c\left(\tau_{a}-\tau_{b}\right)}{2}
$$

Where $\mathrm{c}=$ the wave propagation of $299.79 \mathrm{~m} / \mathrm{sec}$ (. . $1 \mathrm{ft} / \mathrm{ns})$

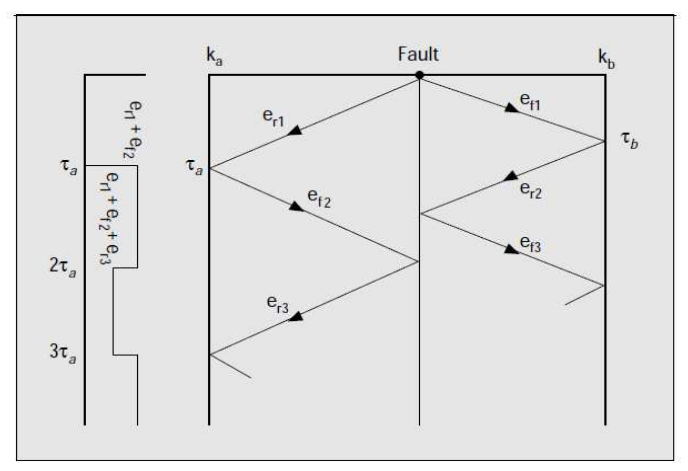

Figure 7.4. Bewley Lattice Diagram.

\subsection{Fault Location Signal Processing Techniques}

A traveling wave, a sharply varying signal, is a real challenge for the traditional mathematical methods. Typically, the traveling waves are mingled with noise as the traveling wave based fault location systems require a high sampling rate so that the fault information can be estimated accurately. The analysis is carried out using TW output signals from the MATLAB simulations for a typical power system with a single circuit overhead transmission line connecting two $500 \mathrm{kV}$ buses as depicted in Figure 7.5.

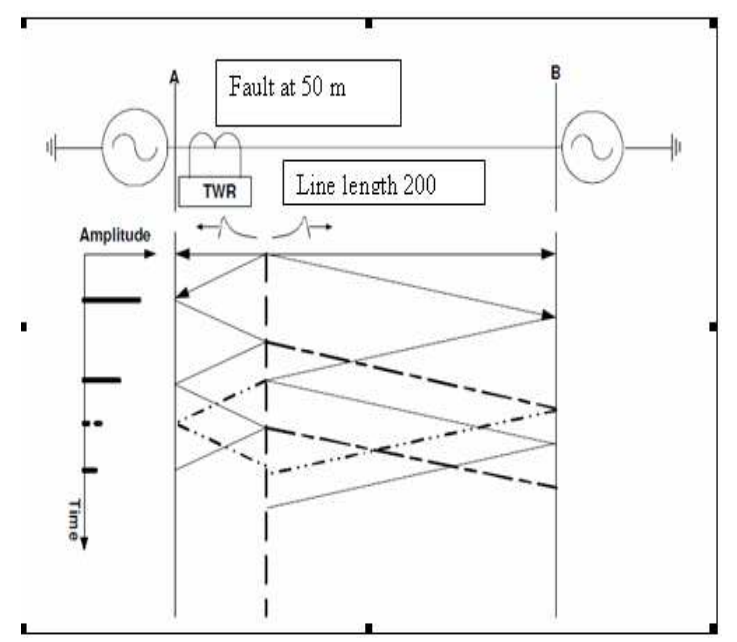

Figure 7.5. Lattice diagram for a fault at the first half of a transmission line. 


\section{Frequency Domain Approach}

Fourier transform based fault location algorithms have been proposed since a long time. Most of the proposed algorithms use voltages and currents between fault initiation and fault clearing. To find out the frequency contents of the fault signal, several transformations can be applied, namely, Fourier, STFT, and Wavelet etc.

\section{Fourier Transform}

Fourier transform (FT) is the most popular transformation that can be applied to traveling wave signals to obtain their frequency components appearing in the fault signal. Usually, the information that cannot be readily seen in the time domain can be seen in the frequency domain. The FT and its inverse give a one to one relationship between the time domain $\mathrm{x}(\mathrm{t})$ and the frequency domain $\mathrm{x}(\omega)$.Given a signal $\mathrm{I}(\mathrm{t})$, the FT FT $(\omega)$ is defined by the following equation

$$
F T=\int_{-\infty}^{\infty} I(t) \cdot e^{-j \omega t} d t
$$

\section{Time Frequency Domain Approach}

The traveling wave based fault locators utilize high frequency signals, which are filtered from the measured signal. Discrete Fourier Transform (DFT) based spectral analysis is the dominant analytical tool for frequency domain analysis. However, the DFT cannot provide any information of the spectrum changes with respect to time.

\section{Short Time Fourier Transform}

To overcome the shortcoming of the DFT, short time Fourier transform (STFT, Denis Gabor, 1946) was developed. In the STFT defined below, the signal is divided into small segments which can be assumed to be stationary. The signal is multiplied by a window function within the Fourier integral. If the window length is infinite, it becomes the DFT.

$$
\operatorname{STFT}(t, \omega)=\int_{-\infty}^{+\infty} I(t) \cdot w(t-\tau) \cdot e^{-j \omega t} d t
$$

Where $I(t)$ is the measured signal, $\boldsymbol{\omega}$ is frequency, $\mathrm{w}(\mathrm{t}-\tau)$ is a window function, $\tau$ is the translation, and $\mathrm{t}$ is time.

To separate the negative property of the DFT described above, the signal is to be divided into small enough segments, where these segments (portion) of the signal can be assumed to be stationary.

\section{Wavelet Transform}

The wavelet multiresolution analysis is a new and powerful method of signal analysis and is well suited to traveling wave signals. Wavelets can provide multiple resolutions in both time and frequency domains. The windowing of wavelet transform is adjusted automatically for low and high frequencies i.e., it uses short time intervals for high frequency components and long time intervals for low frequency components.

Given a function $\mathrm{x}(\mathrm{t})$, its Continuous Wavelet Transform (CWT) is defined as follows

$$
\text { CWT }=(a, b)=\frac{1}{\sqrt{a}} \int_{-\infty}^{+\infty} x(t) \psi^{*}\left(\frac{t-b}{a}\right) d t
$$

The transformed signal is a function with two variables $b$ and $\mathrm{a}$, the translation and the scale parameter respectively. $\psi(\mathrm{t})$ is the mother wavelet, which is a band pass filter and $\psi^{*}$ is the complex conjugate form. The factor $\frac{1}{\sqrt{a}}$ is used to ensure that each scaled wavelet function has the same energy as the wavelet basis function. It should also satisfy the following admissible condition

$$
\int_{-\infty}^{\infty} \psi(t) d t=0
$$

The term translation refers to the location of the window. As the window is shifted through the signal, time information in the transform domain is obtained. a is the scale parameter which is inversely proportional to frequency. Wavelet transform of sampled waveforms can be obtained by implementing the DWT, which is given by

$$
\begin{aligned}
& D W T(k, n, m)= \\
& \frac{1}{\sqrt{a_{0}^{m}}} \sum x[n] \psi\left(\frac{k-n b_{0} a_{0}^{m}}{a_{0}^{m}}\right)
\end{aligned}
$$

Where $\psi(\mathrm{t})$ is the mother wavelet, and the scaling and translation parameters $\mathrm{a}$ and $\mathrm{b}$ in $(313)$ are replaced by $\mathrm{a}_{0}^{\mathrm{m}}$ and $n b_{0} a_{0}^{m}$ respectively, $n$ and $m$ being integer variables. In the standard DWT, the coefficients are sampled from the CWT on a dyadic grid.

The wavelet coefficients (WTC) of the signal are derived using matrix equations based on decomposition and reconstruction of a discrete signal. Actual implementation of the DWT involves successive pairs of high pass and low pass filters at each scaling stage of the DWT. This can be thought of as successive approximations of the same function, each approximation providing the incremental information related to a particular scale (frequency range). The first scale covers a broad frequency range at the high frequency end of the spectrum and the higher scales cover the lower end of the frequency spectrum however with progressively shorter bandwidths. Conversely, the first scale will have the highest time resolution. Higher scales will cover increasingly longer time intervals.

\subsubsection{Case I Single End}

The system is simulated at different locations along the line. A sampling time of $3.333 \times 10^{-9} \mathrm{sec}$ is used for all simulations and propagation speeds of $289900 \mathrm{~km} / \mathrm{s}$. The voltage waveform with multiple reflections is loaded to wavelet toolbox

The distance is calculated as

$$
\begin{aligned}
& \boldsymbol{x}=\boldsymbol{v} \frac{\boldsymbol{d} \boldsymbol{t}}{2} \\
& x=\frac{289900\left(1.849 \times 10^{5}-0.849 \times 10^{5}\right) \times 3.333 \times 10^{-9}}{2} \\
& =48.31 \mathrm{~km}
\end{aligned}
$$


for $L G$ fault at $50 \mathrm{~km}$

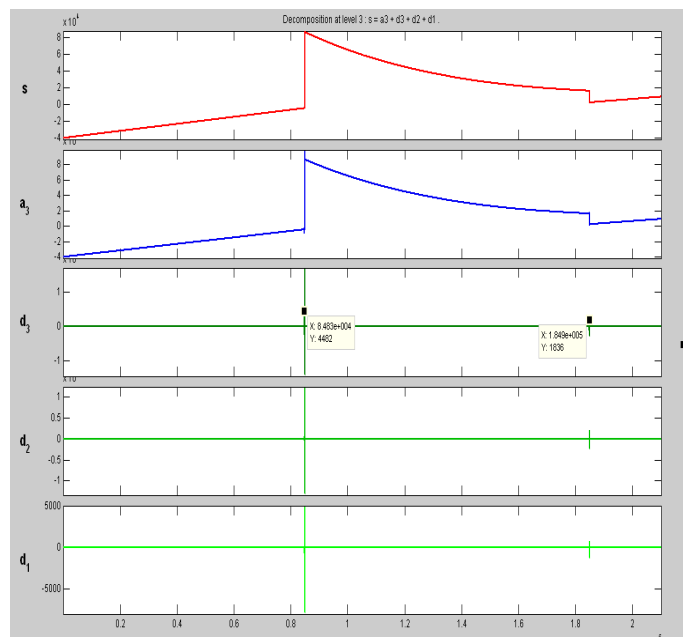

Fig. 7.5.1(a) Voltage Waveform for $L$ G fault at $50 \mathrm{~km}$ with Wavelet Transform.

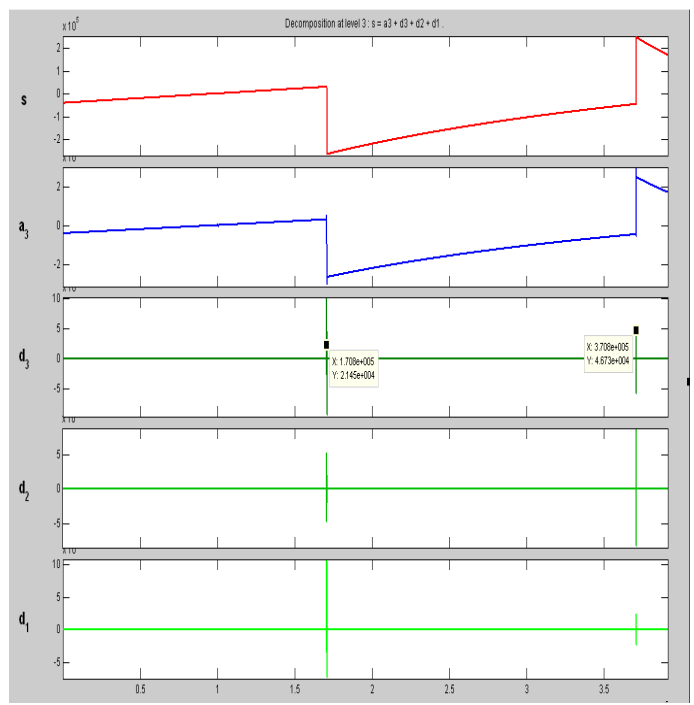

Fig. 7.5.1(b) Voltage Waveform for L L fault at $100 \mathrm{~km}$ with Wavelet Transform.

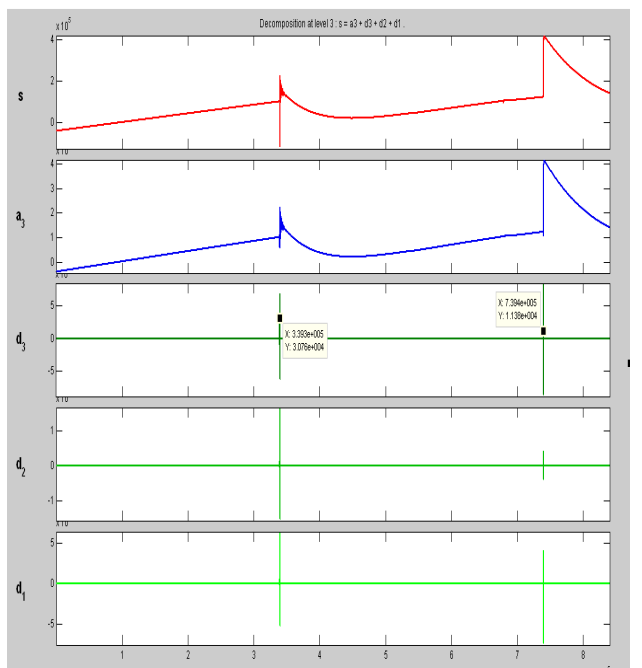

Fig. 7.5.1(c) Voltage Waveform for $L L$ G fault at $200 \mathrm{~km}$ with Wavelet Transform.

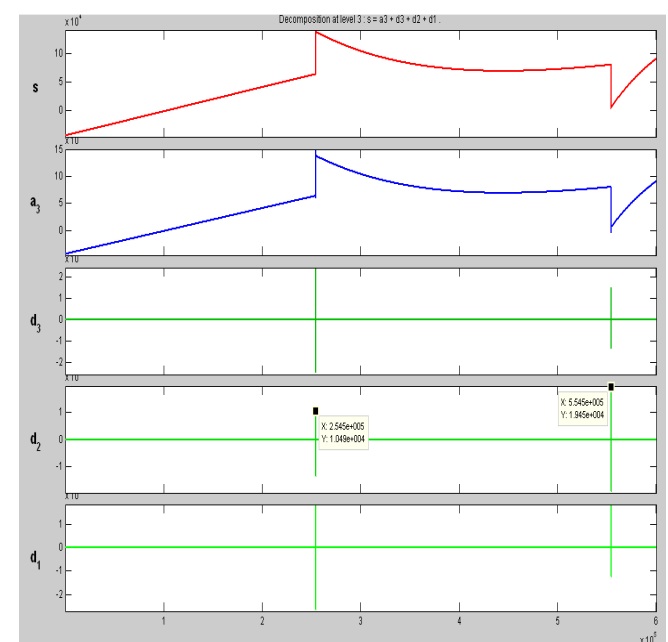

Fig. 7.5.1(d) Voltage Waveform for Symmetrical faults at $150 \mathrm{~km}$ with Wavelet Transform.

Table 7. Location of Faults using single end method for a $200 \mathrm{~km}$ transmission line with Wavelet transforms.

\begin{tabular}{|c|c|c|c|c|c|c|c|c|}
\hline Fanlt & \multicolumn{2}{|c|}{ L-G } & \multicolumn{2}{|l|}{ L-L } & \multicolumn{2}{|l|}{ L-L-G } & \multicolumn{2}{|c|}{ LLLLLLG } \\
\hline $\begin{array}{l}\text { Distalice } \\
\text { (Kim) }\end{array}$ & $\begin{array}{l}\text { Calculated } \\
\text { Distance } \\
\text { (km) }\end{array}$ & $\%$ error & $\begin{array}{l}\text { Calculated } \\
\text { Distance } \\
\text { (km) }\end{array}$ & $\%$ error & $\begin{array}{l}\text { Calculated } \\
\text { Distance } \\
\text { (km) }\end{array}$ & $9 \%$ error & $\begin{array}{l}\text { Calculated } \\
\text { Distance } \\
\text { (kim) }\end{array}$ & \% elror \\
\hline 25 & 24.16 & $-3,34$ & 24.16 & -3.34 & 24.16 & -3.34 & 24.16 & -3.34 \\
\hline 50 & 48.32 & $-3,34$ & 48.32 & -3.34 & 48.32 & -3.34 & 4832 & -3.34 \\
\hline 75 & 72.48 & $-3,34$ & 72.48 & -3.34 & 72.48 & $-3,34$ & 72.48 & -3.34 \\
\hline 100 & 96.62 & -3.35 & 96.62 & -3.35 & 96.62 & -3.35 & 96.62 & -3.35 \\
\hline 125 & 120.81 & -335 & 120.81 & -3.35 & 120.81 & -3.35 & 120.81 & -335 \\
\hline 150 & 144.93 & -3.34 & 144.93 & -3.34 & 144.93 & -3.34 & 144.93 & $-3,34$ \\
\hline 175 & 169.57 & $-3,35$ & 169.57 & -3.35 & 169.57 & -3.35 & 169.57 & -3.35 \\
\hline 200 & 193.29 & -3.34 & 193.29 & -3.34 & 193.29 & -3.34 & 193.29 & -3.34 \\
\hline
\end{tabular}

\section{Conclusion}

In this thesis presented a fault locator that is based on the characteristics of the travelling waves initiated from the fault. This part of the work has addressed the problem of fault distance estimation utilising the measurements of currents as well as voltage travelling wave signals single area and two area transmission line systems. The travelling wave theory was introduced and the properties of the travelling waves on transmission lines were also discussed. The objective of this thesis was to propose an automated technique based on travelling waves for finding the fault location in transmission lines and to test the performance of the technique. The proposed method uses the measured fault current signals of the fault signals. The error in fault location estimation is a function of the sampling rate and the speed of propagation. The techniques were tested using data generated by executing various cases in MATLAB/SIMULINK. Various types of faults were applied at various locations on the transmission lines. It is possible to achieve greater accuracy with multi end methods devel- 
oped in this manuscript compared to the traditional fault location methods.

\section{References}

[1] Lin Yong Wu, Zheng You He, Qing Quan Qian “A New Single Ended Fault Location Technique Using Travelling Wave Natural Frequencies" Chengdu, China, 2009.

[2] Du Lin, Pang Jun, Sima wenxia, Tang Jun, Zhou jun "Fault location for transmission line based on traveling waves using correlation analysis method" 2008 international conference on high voltage engineering and application,chongqing,china,November 9 13,2008.

[3] Bian Haihong and Xu Qingshan "Study of Fault Location for Parallel Transmissions Lines Using One Terminal Current Traveling Waves" DRPT2008 69 April 2008 Nanjing China.

[4] ZOU Gui bin GAO Hou lei, "Algorithm for Ultra High Speed Travelling Wave Protection with Accurate FaultLocation" 2008 IEEE.

[5] Magnus Ohrstrom, Martin Geidl, Lennart Soder, Goran Andersson "evaluation of travelling wave based protection schemes for implementation in medium voltage distribution systems" C I R E D, 18 th International Conference on Electricity Distribution, Turin, 69 June 2005.

[6] S. Jamali and A. Ghezeljeh "fault location on transmission line using high frequency travelling waves" The Institution of Electrical Engineers, Iran,2004

[7] X Z Dong, M A Redfern, Z Bo, and F Jiang “ The Application of the Wavelet Transform of Travelling Wave Phenomena for Transient Based Protection" International Conference on Power Systems Transients - IPST 2003 in New Orleans, USA.

[8] Michael A.street “ delivery and application of precise timing for a travelling wave power line fault locator system. This paper describes BPA's fault locator system" IEEE transaction power delivery.

[9] Qin Jian Chen Xiangxun Zheng Jianchao "Travelling Wave Fault Location of Transmission Line Using Wavelet Transform" IEEE transaction power delivery, China.

[10] N. C. Pahalawaththa, G. B. Ancell, "maximum likelihood estimation of fault location on transmission lines using travelling waves" IEEE Transactions on Power Delivery. Vol. 9, No. 2, April 1994.

[11] Hathaway Telefault TWS Technical Data Sheet, "Traveling wave locator", H.V. TEST (PTY) LTD, South Africa, Online http //www hvtest co
za/Company/PDF/Hathaway/TWSMkIIIBrochure pdf

[12] T. Takagi, J. Baba, K. Uemura, T. Sakaguchi, "Fault protection based on traveling wave theory, Part 1 Theory", IEEE PES Summer Meeting, 1977, Mexico City, Mexico, Paper No. A 77, pp. 7503.

[13] H. Dommel, J. Mitchels, "High speed relaying using traveling wave transient analysis", IEEE PES Winter Power Meeting, New York, Jan. 1978, pp. 214219.

[14] T. Takagi, J. Baba, K. Uemura, T. Sakaguchi, "Fault protection based on traveling wave theory. Part 2 Sensitivity analysis and laboratory test", In IEEE PES Winter Meeting, New York City, 1978, Paper No. A 78, pp. 220226.

[15] P.A. Crossley and P.G. McLaren, "Distance protection based on traveling waves", IEEE Trans. Power Apparatus Syst. PAS 102 (1983), pp. 29712983.

[16] Y. G. Paithankar and M. T.Sant, "A new algorithm for relaying and fault location based on auto correlation of travelling waves ", Electric Power Systems Research, Vol. 8, 2, March 1985, pp. 179185.

[17] E. Shehab Eldin and P.McLaren, "Traveling wave distance protection problem areas and solutions", IEEE Trans. Power Delivery, 3, (1988), pp. 894902.

[18] S. Rajendra, P. G. McLaren, "Traveling wave techniques applied to protection of teed circuits Principle of traveling wave techniques", IEEE Trans PAS, 1985, 104, pp. 35443550 .

[19] S. Rajendra, P. G. McLaren, "Traveling wave techniques applied to the protection of teed circuits Multi phase/multi circuit system”,'IEEE Trans PAS 1985, 104, pp. 35513557.

[20] [20] D. Thomas, A. Wright, "Scheme, based on travelling waves, for the protection of major transmission lines", IEEE Proc. C, 1988, pp. 6373.

[21] C. Aguilera, E. Orduna, G. Ratta, "Adaptive Noncommunication Protection Based on Traveling Waves and Impedance Relay", IEEE Transactions on Power Delivery, Vol. 21, 3, July 2006, pp. 11541162.

[22] C. Aguilera, E. Orduna, G. Ratta, "Directional Traveling Wave Protection Based on Slope Change Analysis", IEEE Transactions on Power Delivery, Vol. 22, 4, Oct. 2007, pp. 20252033.

[23] Power System Relaying Committee IEEE Std C37.114 2004, "IEEE Guide for Determining Fault Location on AC Transmission and Distribution Lines", 2005, E ISBN 073814654 4.

[24] B. M. Weedy, B. J. Cory, "Electric Power Systems", 4th edition, 1998, John Wiley \& Sons Ltd. 